\title{
Validating the Diathesis-Stress Model Based Case Conceptualization Procedure in Cognitive Behavioral Therapies: The LIBET (Life Themes and Semi-Adaptive Plans_Implications of Biased Beliefs, Elicitation and Treatment) Procedure
}

\author{
Sandra Sassaroli ${ }^{2,3,4} \cdot$ Gabriele Caselli $^{2,3,4,7} \cdot$ Giovanni Mansueto $^{3,4}$. \\ Sara Palmieri ${ }^{3,4}$. Alessandro Pepe P Guido Veronese $^{5,6}$. \\ Giovanni M. Ruggiero ${ }^{1,2,3,4}$ (D)
}

Accepted: 2 July 2021 / Published online: 28 October 2021

(C) The Author(s) 2021

\begin{abstract}
Cognitive behavioral therapy (CBT) approaches use case formulation procedures based on the diathesis-stress conceptualization model, arranged in two dimensions: emotional vulnerability (present in a patient's consciousness in terms of core beliefs) and coping strategies. Nevertheless, despite its pivotal role, there are a limited number of validation studies for this model. Life themes and semi-adaptive plans: Implications of biased beliefs, elicitation and treatment (LIBET) is a CBT case formulation method grounded on the CBT diathesis-stress model that aims to help validate the CBT case formulation model, and, in particular, its bidimensional arrangement. In LIBET, the two classic CBT dimensions are called "life themes," which are mental states of focused attention to emotional sensitivities represented as core beliefs in consciousness, and "semi-adaptive plans," which are the rigid management strategies of "life themes" implemented by adopting coping strategies such as anxious safety behaviors, compulsive controls and aggressive or rewarding strategies. The study uses quantitative textual analysis to validate the LIBET procedure in a clinical sample. The investigation discusses the extent to which the results can be considered a validation of the arrangement of the general CBT diathesis-stress model in the two dimensions of core beliefs and coping strategies.
\end{abstract}

Keywords Core beliefs · Coping strategies · Case formulation · Case conceptualization · Diathesis-stress · Validation

Giovanni M. Ruggiero

gm.ruggiero@studicognitivi.net

Extended author information available on the last page of the article 


\section{Introduction}

\section{Theoretical Foundation of CBT Case Formulation: Diathesis-Stress Model}

Case formulation in cognitive behavioral therapy (CBT) approaches is the therapeutic procedure by which the therapist ascertains and shares with the patient in session a psychological explanation of their emotional disorder, and provides a rationale for the specific CBT intervention (Beck, 1976; Beck et al., 1979; Bruch, 1998, 2015; Clark \& Beck, 2010; Clark et al., 1999; Dobson \& Khatri, 2000; Dobson et al., 2018; Ellis \& Grieger, 1986; Kuyken, 2006; Kuyken et al., 2008; Mahoney, 1974; Meichenbaum, 1977; Rachman, 1977; Ruggiero et al., 2021; Sturmey, 2009; Wells \& Mathews, 1994, p. 2). In CBT, case formulation is grounded on the diathesis-stress model of psychological suffering proposed by Beck and colleagues (Beck, 1976, 2008; Beck \& Bredemeier, 2016; Clark \& Beck, 2010; Dobson et al., 2018), which explains the emergence of an emotional disorder in terms of a developmental and emotional vulnerability precipitated by stressful triggers, maintained by negative and self-defeating cognitive schemata, which include both emotional vulnerabilities represented in terms of verbalizable self-related cognitions called core self-beliefs (Beck, 2011, p. 233), and rigidified dysfunctional behaviors called coping strategies (Beck, 2011, p. 204).

These schemata are thought to remain dormant until they are activated by stressful experiences. When activated, the schemata are represented in consciousness and verbalized as cognitions, mainly about the self (Bandura, 1977, 1988; Markus, 1977; Neisser, 1967) but also about the world, the future and human relationships (Beck, 2011). However, self-related cognition seems to play a more pivotal role than other cognition: self-knowledge for many authors-either cognitive, such as Bandura (1977), Markus (1977), and Neisser (1967), or not, such as Erikson (1950), Hermans (1996a, 1996b, 2002), Kohut (1977), and Rogers (1977)—provides consistency, continuity, coordination, guidance, identity, and integration for mental states and is a guarantee of good psychological functioning. The schemata are maintained by coping strategies when they are rigidified in dysfunctional safety or reactive behaviors (Beck, 2008; Beck, 2011; Clark \& Beck, 2010).

Actually, not only Beck's cognitive therapy (CT; Beck, 2011) but also other cognitive (but not CT) models emphasize conscious self-related thoughts and stress the role of personal meanings (Bruner, 1973), such as the constructivist models by Kelly (1955), Mahoney (1974, 1991, 2003), Guidano and Liotti (1983) and others. The diathesis-stress hypothesis is assumed by Ellis's rational emotive behavior therapy (REBT; Ellis, 1962; Ellis \& Grieger, 1986), as emphasized by David et al., (2005, pp. 198-199).

Despite this connection, validation of the diathesis-stress scientific foundation of CBT approaches has developed without much explicit reference being made to CBT case formulation. CBT therapists generally attribute a pivotal role to case formulation that is not merely instrumental, but theoretically consistent with the main focus of CBT (Bieling \& Kuyken, 2003; Butler, 1998; Persons \& Tompkins, 
1997), and regard case formulation as a vital part of their practice (Flitcroft et al., 2007). Although a good case formulation is generally related to therapeutic outcomes (Eells, 2007, 2011, 2015), however, the validity and reliability of the case formulation process in CBT, and in other psychotherapeutic approaches, are only beginning to be studied. In fact, the number of publications devoted to case formulation is still small, and in the order of tens compared to hundreds of studies (or more) exploring therapeutic procedures and their efficacy. The results of these studies are not conclusive, being limited to inter-rater reliability (Mumma \& Smith, 2001; Persons \& Bertagnolli, 1999) and construct validity studies (Kuyken et al., 2008). Judith Beck is among the first scholars to have provided a detailed and operational description of the therapeutic use of case formulation in Beck's CT, known as the cognitive conceptualization diagram (CCD; Beck, 2011, p. 200). Although the procedure for implementing the CCD formulation is well developed, however, its validation-as well as that of other case formulation procedures-remains imperfect, as reported by Eells $(2007,2011,2015)$.

There are also controversial results that suggest the need for further case formulation validation studies. For example, whilst studies suggest that high-quality case formulation is important and promising for intervention planning (Beck, 2011; Ghaderi, 2006; Needleman, 1999; Schneider \& Byrne, 1987; Strauman et al., 2006), they have not yet demonstrated the direct impact of cognitive case formulation on improved CBT outcomes (Chadwick et al., 2003; Nelson-Gray et al., 1989; Schulte et al., 1992). There is also evidence that case formulation may not be entirely positive, with some clients reporting being upset and overwhelmed by cognitive case conceptualizations (Evans \& Parry, 1996; Pain et al., 2008).

Of course, this unsatisfactory situation does not mean that the validity and reliability of the case formulation procedures have never been studied. There is some emerging evidence that training, therapist experience, competence, and the use for more structured procedures of conceptualization improve case formulation reliability (Kuyken et al., 2005; Persons \& Bertagnolli, 1999). It has been confirmed that CBT therapists with greater expertise are more likely to produce more coherent and significant case formulations (Kendjelic \& Eells, 2007; Kuyken et al., 2005; Mumma \& Mooney, 2007). Some studies have demonstrated that CBT case formulations in clinical settings and randomized controlled trials are comparable in effect size (Kuyken, 2001; Persons et al., 2006). These results are all applicable to Beck's CCD (Kuyken et al., 2005), however, they are still insufficient and controversial and further validation studies on CBT case conceptualization procedures are therefore needed. Such studies could confirm both the diathesis-stress scientific foundation of CBT approaches and the role and efficacy of case formulation in the therapeutic process. This work attempts to answer this need.

\section{Subdimensions of the Diathesis-Stress Model}

The lack of studies that validate the CBT case formulation could lead to an insufficient validation of the diathesis-stress CBT model itself, the demonstration of which seems to be guaranteed only by the efficacy studies of CBT. The effectiveness of 
CBT does not automatically demonstrate the validity of the diathesis-stress model, however. A more solid confirmation of the diathesis-stress model could come from the validation of a CBT case formulation model that closely shares the organization of the CBT diathesis-stress model.

For example, an aspect of both the diathesis-stress theoretical model and its corresponding CBT case formulation that remains imperfectly explored and validated, is its bidimensional arrangement in core self-beliefs and coping strategies. We would expect to find many in-depth validity studies on this arrangement, however, the reality is unsatisfactory. We can find some descriptions of core self-beliefs in the CBT clinical literature - the best examples being Judith Beck's classification of cognitive self-beliefs (Beck, 2011, p. 233) and the constructivist personality organizations outlined by Guidano and Liotti (1983, pp. 171-306) and Mahoney (2003)—but no real validation study of these models. Table 1 reports these CBT classifications of self-knowledge.

The picture is no different with regard to the other domain of the CBT diathesis-stress model, i.e., dysfunctional coping strategies that maintain activated core self-beliefs. There does not seem to be an exhaustive classification of coping strategies seems not to be present in Beck's works, which are largely focused on avoidant safety behaviors (Beck, 2011, p. 204), thereby overlooking: (1) controlling strategies aimed at preventing threats, as occur in obsessive compulsive disorder (Barlow, 2002; Moulding \& Kyrios, 2006; Rachman, 1993; Salkovskis, 1985, 1991; Thwaites \& Freeston, 2005) and in eating disorders (Button, 1985, 2005; Sassaroli et al., 2008; Shafran et al., 2002); (2) aggressive and reactive strategies aimed at suppressing the perception of threats (Critchfield et al., 2008; DiGiuseppe \& Tafrate, 2001;

Table 1 Core self-beliefs in CBT (Adapted by Beck, 2011, p. 233) self-knowledge in constructive and cognitive therapy approaches

Beck's cognitive therapy self-beliefs (adapted from Beck, 2011, p. 233)

\section{Helpless self}

Defective; Failed; Helpless; Incompetent; Ineffective; Loser; Needy; Not good enough; Out of control; Powerless; Trapped; Victim; Vulnerable; Weak

Unlovable self

Bad; Bound to be abandoned; Bound to be alone;

Bound to be rejected; Defective; Different; Unattractive; Uncared for; Undesirable; Unlikeable; Unlovable; Unwanted

Worthless self

A waste; Dangerous; Do not deserve to live; Evil; Immoral; Toxic; Unacceptable; Worthless
Constructive personality organizations (Guidano \& Liotti, 1983, pp. 171-306; Mahoney, 2003; Mahoney et al. 1995)

Phobic personality organization

Being despised; Being ridiculed; Needing protection; Not amiable; Not in control; Unable to cope; Weak

Depressed personality organization

Abandoned; Being wrong; Disappointed; Failed; Helpless; Isolated; Missing significant ones (loss); Needing approval; Not loved; Rejected; Separated; Worthless

Obsessive personality organization

Controlled; Detached; Doubtful; Guilty; Judgmental; Looking for certainty; Moral; Perfectionistic; Responsible; Restrained; Unemotional

Eating disordered personality organization

Adhering to others' judgment; Craving emotional contact; Dependent; Self-criticizing; Self-deprecating; Undefined 
Martin \& Dahlen, 2005); and (3) rewarding strategies, such as substance abuse and dependent behaviors, aimed at distracting from threats (Allen et al., 2017; Caselli \& Spada, 2015; Dragan, 2015; Spada et al., 2013). An exhaustive classification of coping strategies should include all four categories, as summarized in Table 2.

In conclusion, a classification of core self-beliefs and coping strategies on which there is consensus in the scientific literature seems lacking. A review of the literature suggests that the list of subdimensions of the diathesis-stress model would roughly include three or four core self-beliefs and as many coping strategies, however, further definition is needed in order to distinguish them, and no validation study has yet confirmed their number or classification.

\section{LIBET Case Formulation Development}

Life themes and semi-adaptive plans: Implications of biased Beliefs, Elicitation and Treatment (LIBET) is a CBT case formulation method grounded on Beck's diathesis-stress model which aims to help validate the CBT case formulation model and, in particular, its bidimensional arrangement in core beliefs and coping strategies. LIBET is a procedure that allows the therapist to understand and share with the patient an explanation of their emotional disorder, a rationale for the implementation of the therapeutic procedures selected and a measure for monitoring the progression of the psychotherapy. The LIBET procedure facilitates the development of the diathesis-stress model by conceptualizing it not only in terms of cognitive contents regarding core self-beliefs and coping strategies, but also including a developmental dimension that justifies the mental representability and verbalizability of emotional vulnerability in terms of core self-beliefs as well as a process dimension that justifies the rigidification of coping strategies in dysfunctional behaviors (Sassaroli et al., 2021).

In fact, these two additional developmental and process aspects were already present in Beck's model, and the idea that dysfunctional self-beliefs are rooted in the personal development of the patient existed in the stress-diathesis model as developmental emotional vulnerability (Beck, 1976; Beck, 2008; Beck \& Bredemeier, 2016; Clark \& Beck, 2010; Dobson et al., 2018). This notion is called "relevant childhood data" in CCD procedure (Beck, 2011, p. 201). It was also present in other cognitive (but not CT) approaches that cultivated this aspect (Bannister \& Fransella, 1971; Feixas \& Miró, 1993; Guidano, 1987, 1991; Guidano \& Liotti, 1983; Lorenzini \& Sassaroli, 1995; Mahoney, 1974, 1991, 2003; Neimeyer, 2009; Neimeyer

Table 2 Coping Strategies in CBT
Coping strategies

(1) Avoidant safety behaviors in anxiety disorders

(2) Controlling strategies aimed at preventing threats, as occurs in obsessive compulsive disorder and in eating disorders

(3) Aggressive and reactive strategies aimed at suppressing threats

(4) Rewarding strategies, such as substance abuse and dependent behaviors, aimed at distracting from threats 
\& Mahoney, 1995; Winter \& Viney, 2005). In summary, the developmental aspect of the cognitive diathesis-stress models means that emotional disorders seem to be contingent on early experiences that leave some of the primary emotional needs of the child unsatisfied and that create emotional vulnerability. However, such vulnerability is not mechanically doomed to develop into an emotional disorder because early patterns are characterized by a form of adaptability that is only subsequently compromised in dysfunctional reactions to painful experiences. Unhealthy adult modalities therefore represent a rigid application of functional developmental habits (Young et al., 2003).

LIBET promotes the integration of aspects of process into CBT, as proposed by Hayes and Hoffman (2018) in their process-based CBT model. Again, the importance of process components had already been identified in CBT models, such as by Aaron Beck himself when he described the circle of fear of fear (Beck et al., 1985) or when he claimed the possibility of going beyond beliefs (1997); or even more sharply by Ellis with his seminal concept of secondary $\mathrm{ABC}$, which was a forerunner of metacognitive concepts (DiGiuseppe et al., 2014, pp. 64-65; Sassaroli et al., 2005). However, the exploration of processes owes much to the new generation of CBT, which focuses on psychopathological processes-acceptance and commitment therapy (ACT; Hayes \& Strosahl, 2004), behavioral activation (BA; Kanter et al., 2009; Martell et al., 2001), the cognitive behavioral analysis system of psychotherapy (CBASP; McCullough \& Goldfried, 1999), dialectical behavior therapy (DBT; Linehan, 1993), functional analysis psychotherapy (FAP; Kohlenberg \& Tsai, 1991, 1997), and integrative behavioral couples therapy (IBCT; Christensen et al., 1995) — and metacognitive reflective mental functioning, or metacognitive therapy (MCT; Wells, 2008). This kind of functional cognitivism suggests that emotional disorders do not depend exclusively on biased mental representations of the self (self-knowledge and self-beliefs) as Beck (Beck, 1976) thought. Rather, they rely on the dysfunctional interaction between voluntary and regulatory processes-for example, attention and executive control—and emotionally charged, automatic associative processes (Hayes \& Hoffman, 2018; Kahneman \& Frederick, 2002; Martin \& Sloman, 2013; Sloman, 2002; Stanovich, 1999; Stanovich \& West, 2002; Wells \& Mathews, 1994).

The LIBET model attempts to integrate these process principles into the classical CBT diathesis-stress model by assuming that developmental vulnerability is not sufficient to determine the disorder but, if managed in a flexible way by individuals, can result in only temporary discomfort and not in negative core self-beliefs and dysfunctional coping strategies. In contrast, psychopathology emerges only if the management of the discomfort occurs in rigid ways and when the mind is not aimed at tolerating stress but has the goal of gaining an illusory definitive suppression of emotional pain through the rigid use of coping strategies.

In summary, LIBET is a clinical conceptualization model for emotional disorders that reformulates core beliefs and coping strategies in two processual dimensions: (1) "life themes," defined as mental states of focused attention to emotional sensitivities represented as verbalizable core self-beliefs in consciousness, accompanied by hurting bodily and emotional perceptions influenced by painful or even dangerous experiences during personal development (Bandura, 1977, 1988; Beck, 2011, 
p. 233; Bruner, 1973; Capo and Mancini 2008; Capo et al. 2010; Csikszentmihalyi \& Beattie, 1979; Di Fini \& Veglia, 2019; Frankl, 2006; Guidano \& Liotti, 1983, pp. 171-306; Dodet, 2010; Lorenzini \& Sassaroli, 1995; Jaspers, 1971; Markus, 1977; Neisser, 1967; Panksepp \& Watt, 2011; Schore, 2012a, 2012b; Wells, 2008); and (2) "semi-adaptive plans," or rigid management strategies of "life themes" implemented by adopting coping strategies, such as anxious safety behaviors (Salkovskis, 1991; Thwaites \& Freeston, 2005), compulsive controls (Salkovskis, 1985), and aggressive or rewarding strategies, including desire thinking, anger rumination, impulsive behaviors and dependent behaviors (Critchfield et al., 2008; DiGiuseppe \& Tafrate, 2007; Martin \& Dahlen, 2005; Spada et al., 2013). These strategies are adopted even at the cost of giving up significant areas of personal development. In the long term, therefore, "semi-adaptive plans" hinder personal development and, beyond a certain level of dysfunctionality, may lead to emotional disorders.

This is a preliminary validation study of LIBET that aims to qualitatively explore the content of the two dimensions of emotional vulnerability represented in terms of self-knowledge ("life themes") and coping strategies ("semi-adaptive plans") in a clinical sample. This qualitative validation of LIBET dimensions aims to be a step forward in the validation process of the shared case formulation procedure common to all CBT approaches.

\section{LIBET Assessment Training and Adherence}

The development of the LIBET procedure implies not only the development of a tool for evaluating and sharing case formulation but also the need to develop a training method for its reliable administration and its adherence to the procedures. There has been much reflection on the level of adherence of therapists to the CBT procedures they claimed to apply since the 1990s, including the formulation of the case as the first step of CBT (Ruggiero et al., 2021). Until then, generic CBT training was considered sufficient, which included reading manuals and attending workshops, but a more rigorous level of adherence supervision was needed. An example of this evolution is that reported by Clark when he was invited to apply CBT in the British National Health System (Layard \& Clark, 2014). A similar evolution occurred in our clinical center when it came to developing the LIBET assessment method. We could not limit ourselves to describing a procedure and taking it for granted that clinics applied it by reading an internal manual, but implemented the following steps:

(1) Clinical and theoretical elaboration; in this phase, which took place in the period 2012-2014, the concept of case formulation was critically examined in discussion groups, which were held each Monday morning and consisted of the authors of the paper and other members (described in the section entitled "therapists") of the clinical staff and research team of our institution. Discussions alternated presentations of literature reviews and brainstorming in order to select the theoretical and clinical concepts relevant to the management of case formulation in therapy. In particular, we conceptualized the connection between the theoretical diathesis-stress model and the CCD case formulation procedure, both arranged 
on the two axes of core self-beliefs and coping strategies, and integrated them with developmental, constructivist, and processual concepts in order to evolve the core self-beliefs in life themes and the coping strategies in semi-adaptive plans (Ruggiero et al., 2021).

(2) Test administration. In the second phase, which was held in the 2014-2016 period, tests were administered in which the concepts defined in Phase 1 were still used in an informal way. Tests were administered both between therapists in peer counseling and with patients in clinical sessions. These test administrations were recorded on video or audio and were systematically reviewed by the same Monday morning discussion group as in Phase 1. This group provided proposals, in the form of instructions and interview prompts, to transform the informal test administrations recorded on video or audio into a draft of a formalized testing interview and procedures.

(3) Draft interview. In the third phase, which took place in 2016, the authors of the paper used the list of suggestions developed by the discussion group during Phase 2 to write a draft of a LIBET interview, administration manual and adherence assessment scales. The first draft was developed by the two younger therapists $\mathrm{CR}$ and $\mathrm{AB}$ and the mature psychotherapist FC, and then revised by the authors of the paper. Finally, the authors of the paper, SS, GMR and GC, developed a system for measuring adherence to the procedure. Once the draft was ready, guided pilot administrations were carried out both between therapists in peer counseling and with patients in clinical sessions and their adherence was evaluated. Audio and video recordings of the administration were reviewed by the Monday morning discussion group in order to suggest modifications of the drafts.

(4) Validation of the final version. In the last phase, which is still in progress, preliminary versions of the LIBET interview, manual and adherence scale were published in their final form in both Italian and English (Sassaroli et al., 2016; Sassaroli et al., 2017a, b; 2021).

\section{Method}

\section{Sample}

\section{Patients}

The sample consisted of 86 outpatients recruited from a population undergoing initial assessment for cognitive therapy delivered in the clinical center of the CBT psychotherapy school directed by the first author. Of the 86 patients, $53(61.6 \%)$ were female and $66(76.7 \%)$ were unmarried, while $17(19.8 \%)$ were married and 3 (3.5\%) widowers. The mean age was $36.89 \pm 11.54$ years. The mean years of education were $16.23 \pm 3.01$. Three patients $(3.5 \%)$ had a secondary school degree, 28 $(32.7 \%)$ a high school degree and $55(64.0 \%)$ a university degree. They were all employed and nobody's income was below the poverty threshold as evaluated by the 
website https://www.istat.it/it/dati-analisi-e-prodotti/contenuti-interattivi/soglia-dipoverta of the Italian Institute of Statistics (ISTAT).

The patients had a DSM (Diagnostic and Statistical Manual of Mental Disorders) diagnosis and were in cognitive psychotherapy for either depression or anxiety (or both): 26 patients (30.2\% of the sample) reported major depression (MD), 21 patients $(24.4 \%)$ obsessive compulsive disorder (OCD), and $66(76.7 \%)$ generalized anxiety disorder (GAD), which means that 23 patients had two diagnoses (19 had both MD and GAD and 4 had OCD and GAD) and two patients reported all three diagnoses. In other words, $21 \mathrm{MD}$ patients $(80.8 \%$ of the $26 \mathrm{MD}$ patients) and six OCD patients $(28.6 \%$ of the 21 OCD patients) also had GAD. This data is all in line with the literature regarding anxiety and depression comorbidity (Möller et al., 2016; Pallanti et al., 2011). Although we did not exclude patients with personality disorders from the study, the clinical center in which we recruited the sample treated a population of patients mainly affected by the target disorders of CBT, anxiety and depression, and therefore, we had no patients with primary personality disorder diagnosis in this study. We had 32 patients with some (which means less than three) disordered personality traits but only eight patients with an associated full diagnosis of personality disorder (five avoidant and three borderline) who attended a skills training group treatment in addition to their CBT treatment.

\section{Patient}

Patients were recruited according with the following inclusion criteria: a minimum age of 18 years; adequate written language abilities; and capable of, and interested in, participating in the present research project. Individuals agreed by signing an informed consent form. We excluded patients with severe psychiatric and/or cognitive impairment, as shown by the presence of either (a) a diagnosis of psychotic disorder, acute hypomania or mania or depressive or substance-related disorder episode, or (b) neurological cognitive impairments.

The patients had been treated in CBT therapy during the period 2013-2016 under the care of therapists at the clinical center where the authors work. The psychotherapies lasted from four to nine months, from 16 to 36 sessions if we include the intensive treatment of one weekly session, and if we include the period of maintenance and follow-up the period in treatment ranged from 14 to 24 months.

\section{Therapists}

The therapists included SS (female, 61-65 years old), FC (male, 57-61 years old), GMR (male, 47-49 years old), GC (male, 33-35 years old), AB (male, 36-39 years old) and CR (female, 33-35 years old). All had received training in CBT, although in different forms, reflecting different historical periods. SS and FC attended the first training in CBT psychotherapy not yet recognized by Italian law, with Guidano and Liotti in the early 1980s after studying medicine and specializing in psychiatry. The initial training lasted three years. After an initial non-formalized apprenticeship period in which they were supervised for several years, they were mature psychotherapists who functioned independently. GMR had also studied medicine 
and specialized in psychiatry, but had his training legally recognized by the Italian State under Law 56 of February 18, 1989 on training in psychotherapy. This legally regulated training lasted four years. GMR also had an initial period of informal supervision and then began working as a mature psychotherapist who functioned independently. From 2012, however, GMR adhered to the new model of continuing education that was becoming established, participating assiduously in specific training in rational emotive behavior therapy (REBT, Ellis \& Grieger, 1986) (2012-2016) at the Ellis Institute in New York, USA, MetaCognitive Therapy (MCT, Wells, 2008) (2016-2019) at the MCT Institute in Manchester, UK, and CBT (2016-2019) at the Beck Institute in Philadelphia, USA, or online and undergoing formalized periods of supervision. Finally, after graduating in psychology, GC, AB, and CR had their training in psychotherapy recognized by the Italian State according to Law 56, and they too, after the official training, undertook various courses of continuing education, including additional courses and supervision formalized in various orientations: $\mathrm{AB}$ in mindfulness and acceptance and commitment therapy (ACT, Hayes \& Strosahl, 2004), GC in MCT and CR in eye movement desensitization reprocessing (EMDR; Shapiro, 2017) and REBT.

\section{Instruments}

All the measures listed below, including the LIBET case formulation, were implemented at the beginning of the therapy within the first four sessions. The clinician started treatment by evaluating LIBET, and by sharing it with the patient during the fourth session.

\section{Psychopathological Evaluation}

Psychiatric symptoms were evaluated using the structured clinical interview (SCID) for DSM-5 (American Psychiatric Association, 2013; First et al., 2015a, 2015b). We used the officially approved Italian version of the SCID diagnostic interview starter kit for DSM-5 called SCID-5-CV (Intervista clinica strutturata per i disturbi del DSM-5®_Versione per il Clinico). The publication reports all the validation data of the Italian version (Borroni \& Fossati, 2017). The used the second version of the Beck depression inventory (BDI-II, Beck et al., 1996) which was updated from the original version of the Beck depression inventory (BDI; Beck et al., 1961), and fits with the diagnostic criteria of major depressive episodes of the DSM (Beck et al., 1996a, 1996b). We used the Italian translation of the instrument that was approved by the authors of the original version and replicates its validation data (Ghisi et al., 2006; Montano \& Flebus, 2006).

The Padua Inventory Scale (Sanavio, 1988) is a self-report measure of obsessive-compulsive behaviors, which shows good internal consistency as well as convergent and divergent validity with other validated instruments both in the original Italian version and in the English translation (Sternberger \& Burns, 1996).

The State-Trait Anxiety Inventory (STAI- Form Y) (Spielberger et al., 1983) is a self-report measure of obsessive-compulsive behaviors, which shows good internal 
consistency as well as convergent and divergent validity. We used the Italian translation of the instrument that is approved by the authors of the original version and replicates its validation data (Pedrabissi \& Santinello, 1989).

\section{Case Formulation Evaluation}

LIBET life themes and semi-adaptive plans were assessed using the LIBET interview procedures as published in Italian and English journals and books (Sassaroli et al., 2016; Sassaroli et al., 2017a, b; 2021), which report in more detail the information described in the following section of this paper entitled "LIBET assessment training and adherence." Here we provide some general information about this procedure.

The LIBET case formulation procedure refers to the techniques of the main CBT approaches, that is standard CBT (Clark \& Beck, 2010), REBT (DiGiuseppe et al., 2014; Ellis \& Grieger, 1986) and the cognitive therapies of the constructivist tradition (Bannister \& Fransella, 1971; Feixas \& Miró, 1993; Guidano, 1987, 1991; Guidano \& Liotti, 1983; Lorenzini \& Sassaroli, 1995; Mahoney, 1974, 1991, 2003; Neimeyer, 2009; Winter \& Viney, 2005). These approaches all use models of cognitive functional analysis that can be traced back to REBT's ABC framework (DiGiuseppe et al., 2014; Ellis \& Grieger, 1986). They all structure problematic situations into disturbing antecedents (A), dysfunctional thoughts or beliefs (B) and distressing emotions and dysfunctional behaviors (C). The procedure of LIBET also borrows REBT's ABC analysis model and calls this basic element "ABC-LIBET" (ABC-L) and is reported in Table 3.

We have borrowed the idea of using a series of at least three functional analyses of problematic situations from Beck's CBT case formulation (the abovementioned CCD), tendentially (but not necessarily) three and framing these situations in a two-axes structure, which includes either core beliefs and coping strategies in CBT or life themes and semi-adaptive plans in LIBET. Moreover, and this time borrowing from the constructivist tradition, the problem situations are not all located in the present but aim to cover the whole timeline of the patient's developmental process of the problem. The first ABC is located in the present and represents the problem that brought the patient into therapy. At the opposite extreme, there is an $\mathrm{ABC}$ located in the past which represents the first learning of the problematic vulnerabilities and coping strategies of the patient. Between these points we find the $\mathrm{ABC}$ of invalidation-a term borrowed from George Kelly's model (Kelly, 1955)-the situation of crisis in which a patient experienced that their usual behaviors proved ineffective to protect their vulnerabilities but where, instead of flexibly looking for alternative ways, they thought that they should apply the coping strategies even more rigidly, making it wholly dysfunctional. It is also the situation in which the vulnerabilities have pathologically transformed from painful to intolerable because the patient felt that it had become necessary to avoid any mental contact with them. Actually, "invalidation" involves the disconfirmation of a hypothesis in Kelly's personal construct psychology, as an individual's psychological constructs hypotheses about reality. When a personal construct proves to be unable to correctly evaluate reality, 
Table 3 Formulation and case monitoring diagram in LIBET

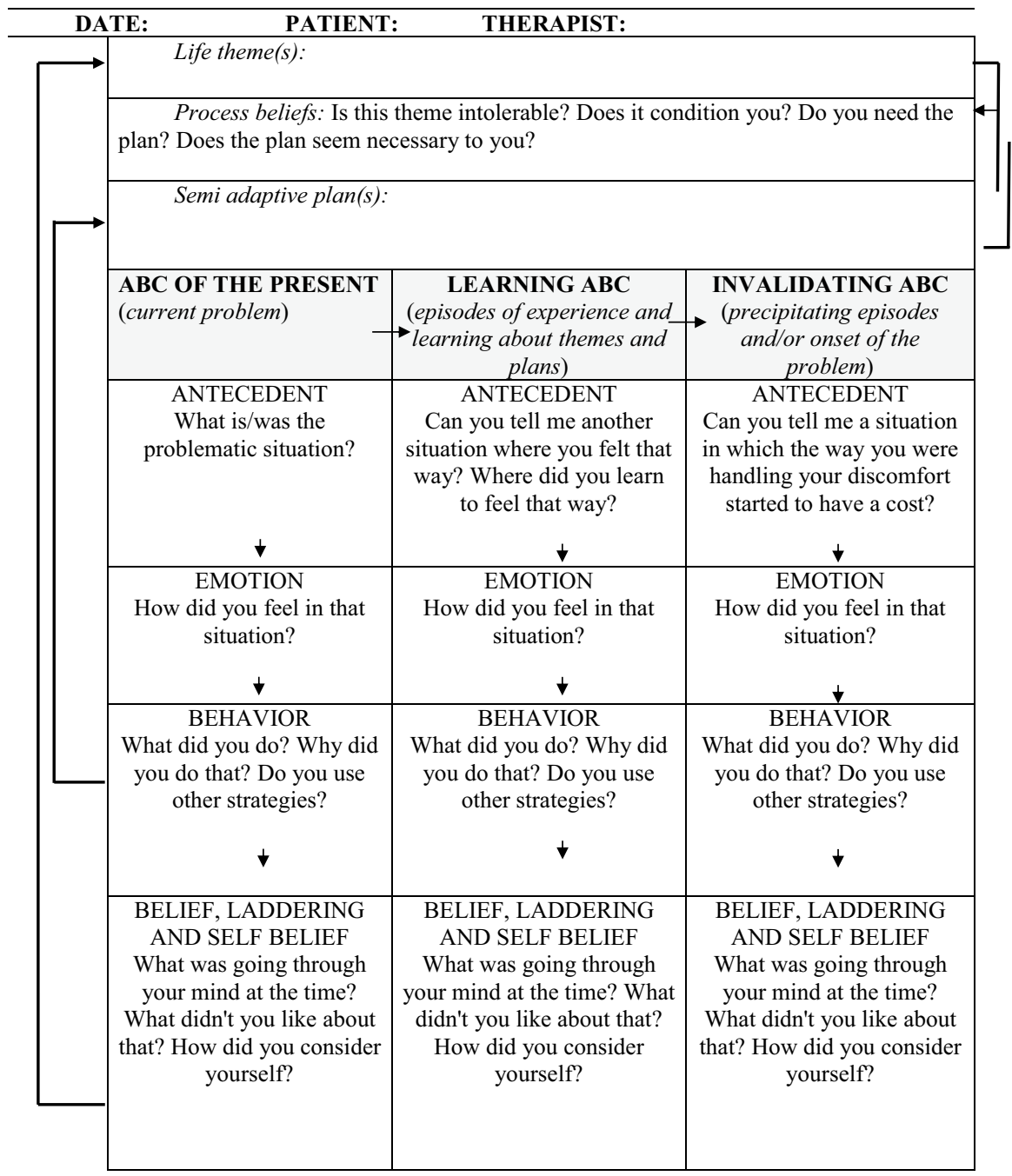

there is an invalidation that is accompanied by an emotional activation that in turn can rigidify becoming an emotional disorder. LIBET, while borrowing the concept of invalidation from Kelly, emphasizes the component of emotional crisis in invalidation.

In addition, the three scenarios, present problem, past learning of the problem, and invalidation are implemented in more than one ABC for each of the three scenarios. Therefore, the therapist aims to look for many examples of the three general situations. Once the $\mathrm{ABCs}$ have been collected, they can then be 
summarized into life themes and semi-adaptive plans, according to the following guidelines.

\section{LIBET Assessment Procedures}

LIBET follows a structured procedure comparable to a clinical interview, and is administered by the psychotherapist during the first sessions as part of the psychotherapy itself. In fact, it provides the patient with a formulation of their case as a general hypothesis for formulating the therapeutic problem, and also as a means of sharing the therapeutic plan and its rational functioning. Two sessions can be sufficient to ascertain LIBET, and more rarely three or at most four sessions. In fact, the basic assumption of the LIBET procedure is that CBT case formulation, either CCD or LIBET, is the initial move and main operational tool of CBT approaches, through which a therapist manages the entire psychotherapeutic process. The idea is that, in CBT, case formulation incorporates both the specific cognitive and behavioral interventions of the treatment and the non-specific components, including the negotiation of the therapeutic alliance and the management of the therapeutic relationship. LIBET is considered part of a project that aims to show how this aspect is increasingly becoming the hallmark of standard CBT approaches because it is in line with CBT's basic principles: it implies full confidence in the conscious agreement between therapist and patient, transparent cooperation, and an explicit commitment to the CBT model of clinical change (Ruggiero et al., 2021).

\section{Preliminary sharing of the LIBET model}

Sharing the case formulation is vital to building a therapeutic alliance, and therefore, during the assessment phase, the therapist explains the LIBET model to the patient. The patient can be approached with a prompt such as follows:

As human beings, all of us have vulnerabilities in our life history that we call life themes. This vulnerability, in some circumstances, can become painful or even intolerable. Over the course of our life, we have also learned strategies that we will call semi-adaptive plans; these have allowed us to manage our life themes. These plans can help us, but when they become rigid and inflexible, they also increase the emotional pain and create other problems. Sometimes that's what we call symptoms. We are going to work together using themes and plans to understand your distress and then find a therapeutic strategy to deal with it.

\section{LIBET Assessment Techniques: $A B C$ and Laddering}

LIBET is not performed by filling in a structured interview form, but by constructing a scheme with the patient, such as that shown in Table 3, on a sheet of paper or on an overhead projector, similarly to how the way a CCD is built in CBT. Therefore, 
and as stated above, the LIBET case formulation procedure starts by using an $\mathrm{ABC}$ analysis model called "ABC-L." The ABC-L begins with the elicitation of a problematic situation, encouraging the patient to be as accurate as possible:

Can you tell me an occasion particularly representative of your problem in which you comprehensively remember the circumstances, the time and place where it happened?

After assessment of the situation, the process addresses emotions and dysfunctional behaviors:

T: What did you feel? What did you do then that didn't help you?

After emotions and behaviors, dysfunctional thoughts are elicited by asking about the immediate conscious thought (What was going through your mind at that moment? What did you think at that moment?) and the following chain of thought, by using various techniques, from the downward arrow of the CBT school (Beck, 2011: pp. 206-208) to the chain inference of the REBT school (DiGiuseppe et al., 2014: pp. 173-174) to the laddering of the Kellian constructivist school (Bannister \& Fransella, 1986; Bannister \& Mair, 1968; Hinkle, 1965; Kelly, 1955). All of them focus primarily on the negative implications of the feared events or moods. The question is:

T: What don't you like in this?

In CBT as well as in LIBET this question is aimed to assess a self-belief. Once we have ascertained the beliefs, we reach a hypothesis of the patient's life theme in its self-descriptive component. The life theme, in fact, is comprised of a cognitive and self-descriptive component (e.g., "I see myself as a failure") and an emotional and viscerally perceptive component, a prevailing, pervasive, and disturbing emotion (e.g., "I feel shame").

After the problem of the present, we have to assess the invalidating situations. As observed above, George Kelly (1955) used the concept of invalidation to indicate the moment when a situation unequivocally disconfirms a predictive hypothesis. In LIBET, the concept of invalidation is applied to a semi-adaptive plan when it becomes non-adaptive. In order to fully explore the dysfunctional elaboration of an invalidation, it is therefore necessary to focus on the episodes related to the onset of the disorders. The invalidation ABC can be ascertained by asking: What was changing in your life before you got sick? When did this behavior stop being useful to you? How didn't it work anymore? Once the invalidation episode has been identified, the patient is encouraged to explore the connection between invalidation and symptomatic onset:

T: Do you see a relationship between this episode and the onset of your problem?

The third step is the link between the life theme and life history. The aim is to identify another $\mathrm{ABC}$ in which the patient is asked for a past situation in which they learned to react in a way akin to what would become their semi-adaptive plan. It is 
possible to either focus on single episodes (e. g., We are now looking for an episode in your past in which you considered yourself as a ... or experienced this emotion of ... in a similar way to the present) or on a more general relational situation with the patient's significant relationships (e.g., Can you tell me something about your relationship with significant people during your childhood and adolescence? How were your relationships like?) As usual, the life theme is found in how the patient saw and considered themself (self-belief): How do you see the child that you were? What did that child want and need? and the plan in the behavior: How did that child react? Has that child learned to handle feeling that way?

Once a number of ABCs have been identified, they can be summarized into a life theme and a semi-adaptive plan. Once again it is good to share it explicitly with the patient: Can we call your vulnerable way of feeling and judging yourself in problematic situations your "life theme"? Can we call your usual behavior in problematic situations your "plan"?

\section{Qualitative Analyses}

The main focus of the present study was to explore LIBET's life themes and semiadaptive plans in a clinical sample using the quantitative textual analysis (QTA) (Bolden \& Moscarola, 2000) method, which integrates two different approaches. The first is a bottom-up approach, according with which the analysis of qualitative textual data was directly applied to transcriptions in order to test whether LIBET's assumed themes and semi-adaptive plans spontaneously emerged from the data.

The second is a top-down approach, according to which we used interpretative categories to identify whether and to what extent the transcribed materials fitted with different categories of life themes and semi-adaptive plans. We therefore started from a number of clinical hypotheses of the variables of core self-beliefs (to be confirmed as life themes) and four coping strategies (to be confirmed as semiadaptive plans). These variables were provided by the aforementioned Monday morning discussion group, which, in the period 2012-2016, outlined the procedures of assessment of the LIBET. The group provided a preliminary list of eight variables composed of four core self-beliefs and four coping strategies drawn from both the scientific literature, as reported in the introduction (subsection "Subdimensions of the diathesis-stress model") and clinical experience. These eight variables were built in order to obtain a list to submit to the statistical selection work that would then validate the most reliable variables.

The self-beliefs/hypothesized life themes included a self-judgement of being:

(1) Threatened, a mental condition in which the individual experiences a feeling of danger and lack of personal safety and protection guaranteed materially and affectively by significant and reliable figures. The threat to this need can bring emotional experiences of unbearable danger in the face of which the individual feels powerless (Herman 1992; van der Kolk, 1996) and in which emotional states of fear are experienced to the point of panic and paralyzing terror, the so-called "freezing" (Herman, 1992; Griskevicius et al., 2010; Mogg \& Brad- 
ley, 2016; Ogden et al, 2006; Ogden et al., 2006; van der Kolk, 1996) and the processing of thoughts and emotions takes place in chaotic, disorganized, and accelerated ways with sudden turns towards dullness, demotivation and anhedonia (Ogden et al., 2006);

(2) Inadequate, i.e., a feeling of lacking personal value and ability learned in an internal and relational environment where the idea that the environment outside the family circle and exploration are challenging and stressful and that the individual alone does not have sufficient personal skills and resources to face the trials of the outside world independently (Bifulco et al., 2006; Feng et al., 2017; Huprich, 2003; Kiernan \& Huerta, 2008). Research on family histories (Fyer et al., 1993) and risk factors (Dierker et al., 1999) highlights the possibility that anxiety is transmitted by the explicit passage of negative information about the world and human relationships (Rachman, 1977) and/or indirectly by modeling and mimesis in the framework of interactions with significant figures (Woodruff-Borden et al., 2002);

(3) Unloved, linked to emotional states of sadness and depression (Beck, 2008; Bifulco et al., 2006; Kiernan \& Huerta, 2008; Huprich, 2003; Hollon et al., 2020; Rimes \& Watkins, 2005). Depressive states are linked to situations in which caring is present but provided in an atmosphere of emotional deprivation and cold and distant affectivity, in which bodily contact is rare and awkward (Kiernan \& Huerta, 2008; Maheu et al., 2010); in subsequent stages of evolution, emotional deprivation and lack of emotional closeness and affectivity can result in a vision of self that is characterized by a sense of loss, emotional abandonment, and futility (Bosquet \& Egeland, 2006; Woodruff-Borden et al., 2002);

(4) Unworthy, i.e., a feeling of exclusion, inferiority and contempt towards oneself (Brewin et al., 1992; Huprich, 2003; Irons et al., 2006; Kawamura et al., 2001; Vieth \& Trull, 1999) linked to an emotional state of shame and guilt (Salkovskis, 1985). In this case it is a self-evaluation that has to do with rank, and the comparison between oneself and others. This sensitivity to unworthiness can arise in families with a severely critical, controlling, demanding, and oppressive relational style. The relational styles of caregivers typical of these relational environments show a significant tendency towards criticism (Hirshfeld et al., 1997), catastrophic thinking in interactive sequences with children (Whaley et al., 1999) and punitive and reprimanding discouragement of the autonomy of the child (Apparigliato et al., 2007; Brewin et al., 1992; Huprich, 2003; Irons et al., 2006; Kawamura et al., 2001; Vieth \& Trull, 1999).

The four coping strategies/hypothesized "semi-adaptive plans" corresponded to:

(1) Avoidant behavior in which the individual systematically attempts to dodge external contexts that could evoke in them adverse stimuli. Such an individual will always live safely but will have little chance to grow and evolve both intellectually and emotionally. Empirical research has shown that behavioral (Blalock \& Joiner, 2000) and cognitive avoidance (Beevers et al., 1999; Rassin et al., 2000) are related to depressive or anxious states (Barlow, 2002; Blalock \& Joiner, 2000); 
(2) Controlling behavior in which the individual constantly seeks to control, prevent or resolve the adverse stimuli they anticipate in their future. In this security framework, the individual believes that their vulnerability can be protected through strict and efficient strategies of hypercontrol (Barlow, 2002; Hoyer et al., 2001; Mineka \& Zinbarg, 1996; Moulding \& Kyrios, 2006; Rapee et al., 1996; Ruggiero et al, 2012; Sassaroli et al., 2008; Shafran et al., 2002; Shapiro \& Astin, 1998, p. 23);

(3) Aggressive and angry behaviors (Critchfield et al., 2008; DiGiuseppe \& Tafrate, 2007; Martin \& Dahlen, 2005) that can be used to achieve emotional detachment as a condition of unassailable superiority over the emotional pain, won at the end of the angry conflict; the individual aims at a final state of immunity to emotional pain, something similar to the concept of the detached self-sufficient individual of Young (1990) and devitalized emptiness elaborated by Dimaggio and Semerari (Dimaggio et al., 2007);

(4) The last conduct identified is the self-rewarding sensation-seeking behavior that manifests itself in addiction and desiring thinking, which aims to anesthetize emotional pain by artificially inducing states of pleasure (Caselli \& Spada, 2015; May et al., 2004; Spada et al., 2013; Tiffany, 1990).

Given that the nature of the LIBET assessment is both conversational and structured, qualitative analyses were carried out using the records of the assessment sessions. The transcripts were then processed directly by the T-LAB 5.0 software without intermediate filtering by human evaluators. T-LAB 5.0 is able to independently select the significant terms for processing, such as nouns, verbs, and adjectives, and omit those that are semantically irrelevant, such as conjunctions, prepositions, and adverbs. Since at least two sessions are sufficient to ascertain the LIBET, and more rarely three or four sessions, the full corpus of 86 interviews was collected in 192 sessions, with an average number of 2.32 sessions for each LIBET interview.

Following the tradition of QTA studies, an initial preprocessing phase was needed to remove all sources of biases included in the qualitative data (e.g., misspelled words). This first step included: normalization (removing all general function words such as articles, connection forms, and prepositions), lemmatization (reducing all inflected words to their root form, as found in a dictionary), and synonymization (words that can be considered equivalent from a semantic point of view; for example, "illness" and "sickness" are reduced to the same root form). The result of this process was a qualitative corpus representing the database in which algorithms of quantitative textual analysis could be applied.

The full corpus of 86 interviews for this research included 7455 occurrences (occurrences are the total number of words in analysis), 1442 root forms (root forms are the total number of words in analysis after lemmatization) and 1182 hapax (these are words appearing only once in the corpus). After adopting a minimum of four as a threshold value for the root forms, the resulting data comprised 152 root forms, 1,440 occurrences and no hapax. The type/token ratio (TTR; TTR is a measure of vocabulary richness obtained by dividing the total number of unique words by the total number of used words in a segment of text) of $24.8 \%$, the root TTR (Guiraud, 1960; the root TTR is a weighted measure of vocabulary richness obtained by dividing the number of words by the square root of the total number of used words) of 
$21.4(\mathrm{~g}=4.16)$ and the mean frequency of words (9.47) suggested that the data was suitable for subsequent analysis with multidimensional scaling (MDS).

The second step of the preprocessing phase was the construction of a co-occurrence matrix, which is a tool able to account for all frequencies of pairwise word co-occurrences (for further details about algorithms and the QTA procedure, see Lancia, 2008; Lund \& Burgess, 1996; Veronese et al., 2019a, 2019b, 2016, 2019a, $2019 b$ ) and that can be analyzed by means of MDS procedures.

\section{Multidimensional Scaling}

MDS (Mugavin, 2008) is a statistical tool of data reduction and exploration able to summarize large amounts of data into more easily grasped spatial maps that are built by reproducing important relationships among data. An important feature of this technique involves to the possibility of portraying the structure of data by rescaling a set of proximity measures into visual distances representing specific locations in a spatial (i.e., Cartesian coordinate system) configuration (Borg et al., 2013). This means that words which tend to be used together in the same unit of analysis appear close in the Cartesian space, whereas words that are further apart indicate dissimilarity. In this study, the selected association index - a measure of semantic proximity between a pair of selected words—was Salton's cosine (Salton \& McGill, 1983). Salton's cosine resembles the logic of the common Pearson correlation coefficient, with values ranging from 0 (no association) to 1 (full association).

MDS analysis provides two different outputs: Sammon's stress measure, which is a sort of goodness-of-fit index ranging from 0 to 1 (Sammon, 1969), and a visual plot of points (words), which provides a graphical representation of data. Information was organized in the Cartesian space according to two criteria: (1) words were organized in terms of similarity/distance and then grouped into "clusters"; and (2), clusters were organized along its axes and polarity. In MDS analysis, axes can ultimately be interpreted through principal component analysis or factor analysis (Kruskal et al., 2006).

In the second stage of MDS analysis (following a top-down approach), the analysis of lexical specificities (ALS) is used to ascertain whether some typical or exclusive words (lexical units) occur in a given subset of text, as defined by an organized categorical variable. It is thus possible to understand whether previously developed categories are semantically saturated by the textual data. ALS adopts $\chi^{2}$ values (in this study, the p-value was set at 0.01) to assess the association between a given subset of text and target words: the greater the $\chi^{2}$, the higher the probability that an association is not due to chance (Nestor \& Schutt, 2014).

\section{Results}

\section{Multidimensional Scaling}

The first result of the QTA pertained to the most frequently used word. Frequently occurring words indicate emerging themes in a textual corpus and provide the basis 
for more complex coding categories. The most frequently occurring words in the transcriptions were: "to feel” (98), "to seek" (88), "to avoid" (52), "anxiety" (41), "to control" (41), "to think" (39), "to worry/ruminate" (the Italian word "rimuginare" can mean either "to worry" or "to ruminate," depending on the context) (37), "situation" (32), "fear" (29), "to handle" (23), "sadness" (23), "sensation" (19), "shame" (15), and "weak" (15). This first glimpse into these words provides a general insight into the textual content, although any analysis of raw numbers is necessarily biased (e.g., the word frequency count is not weighted for length of transcription) and does not allow one to identify underlying structures of data. The model configuration and the results of MDS are reported in Fig. 1.

The model organized words in the bidimensional space in a fairly balanced way, with four main point clouds. The first quarter (red) listed words such as "fear," "to experience," "to lose," "life," "fail," "vulnerable," and "sensation." Here is one example of a statement including such words:

Something bad can happen at any time. [...] I'm afraid to be seen as vulnerable, weak if I'm not always ready to deal with everything. [..] I consider myself shrewd rather than really brilliant ... I'm afraid that other people would notice it, it would be a defeat. [Può succedere qualcosa di brutto in qualsiasi momento. [...] ho paura di essere visto come vulnerabile, debole se non sono sempre pronto a occuparmi di tutto. [..] mi vedo più furbo che intelligente... ho paura che gli altri se ne accorgano, sarebbe una sconfitta].

(Male, 47 years, single).

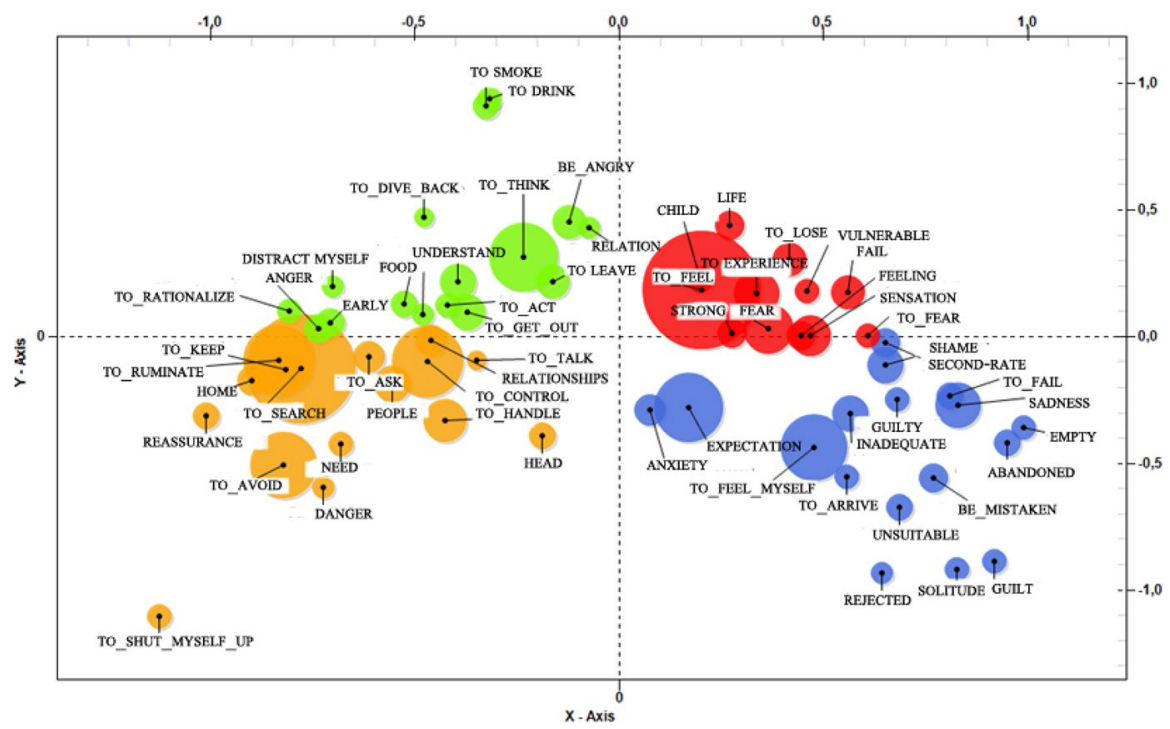

Fig. 1 Exploratory MDS and word coordinates on the Cartesian Space (Summon's stress $=0.124)_{*}$. * colors were assigned randomly, the radius of a circle corresponded to its relative weight, words unit are organized on the base of similarity/dissimilarity (Color figure online) 
The second quarter (blue) listed words such as "guilt," "anxiety," "expectation," "unsuitable," "inadequate," and "abandoned." An example quotation is:

Feeling the criticism, the disappointment ... like when my father's glances made me feel his disapproval [...] Feeling like I had failed to meet his expectations ... Shame, feeling shame. [Sentire la critica, il disappunto... come con mio padre, mi faceva sentire con quel suo sguardo la disapprovazione. [...] Sentire di aver disatteso le aspettative... la vergogna, sentire la vergogna]. (Male, 45 years, married)

The third quarter (yellow) included words such as "to control," "to avoid," "danger," "relationship," "to handle," and "people," with example statements including:

I ask everybody's opinion, but then I do it all by myself. I brood. I try to deal with others by not talking so I stay far away. I do it to handle things, check ... even if it does not work at all. [Chiedo pareri a tutti poi però invece faccio di testa mia. Rimugino. Cerco di gestire con gli altri non dicendo delle cose così sto lontano. Lo faccio per gestire, controllare....anche se poi non serve e niente]. (Male, 44 years, married)

I go loopy, I wonder if that thing is right or wrong. Thus, I try to monitor, to control. [Vado in loop, mi chiedo se quella cosa è giusta o sbagliata. Così cerco di monitorare, di controllare]. (Female, 39 years, married)

Finally, the last quarter (green) was composed of words such as "to smoke," "to drink," "anger," "to distract myself," and "food." Example quotations included:

I smoke, I drink, I try to find something that distracts me, I justify myself. [Fumo, bevo, cerco qualcosa che mi distragga, mi autogiustifico]. (Female, 23 years, single)

I take Bromazepam, I drink two glasses of prosecco every night, I wait all day for that moment. [Prendo il Bromazepam, bevo due prosecchi ogni sera aspettando durante il giorno quel momento]. (Female, 58 years, widow)

\section{Concept Mapping}

The results of multidimensional scaling reported in Fig. 1 suggest concept mapping in four groups of cognitive content. The first area, colored red, indicates states of fragility, danger and threat, failure and defeat. The second area, colored blue, has content corresponding to inadequacy, abandonment, and blame. The third area, colored yellow, corresponds to cognitive content related to controlling and avoiding safety behaviors. Finally, the fourth area, colored green, shows cognitive content related to either dependent behaviors, such as smoking, drinking, or eating, or reactive states such as aggression and anger. 

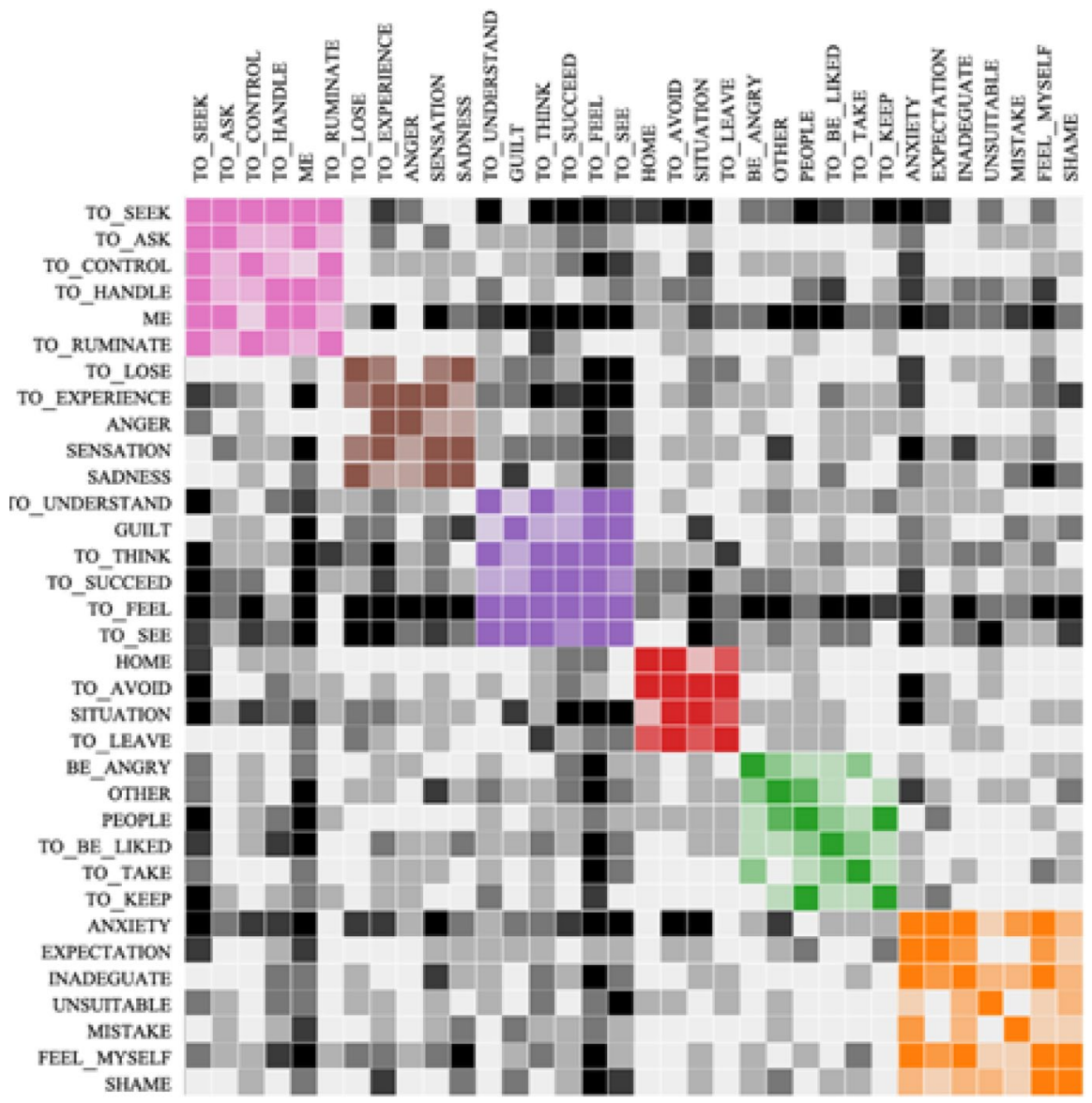

Fig. 2 Co-word analysis and Co-occurrences matrix. Different colors equal to homogeneous group, color shades equal to association weights (Color figure online)

\section{Cosine Association}

Analysis of the cosine associations between words (Fig. 2) provides a more detailed overview of the organization of subordinate groups of words.

As described in the Method section, the results presented in Fig. 2 were produced by a hypothesis-driven analysis of four CBT core self-beliefs (threatened, inadequate, unloved, and unworthy) to be confirmed as LIBET life themes, and four CBT coping strategies (avoidant, controlling, aggressive, and self-rewarding) to be confirmed as LIBET semi-adaptive plans. Our analysis reported in Figs. 2, 3, and 4 actually suggested six areas. According to these results, at least two variables, either themes or plans, were disconfirmed. Which were these? According to the verbal content of the six areas, the first upper-left area in pink corresponds to the words "to see," "to ask," "to control," "to handle," "me," and "to ruminate," seemingly 


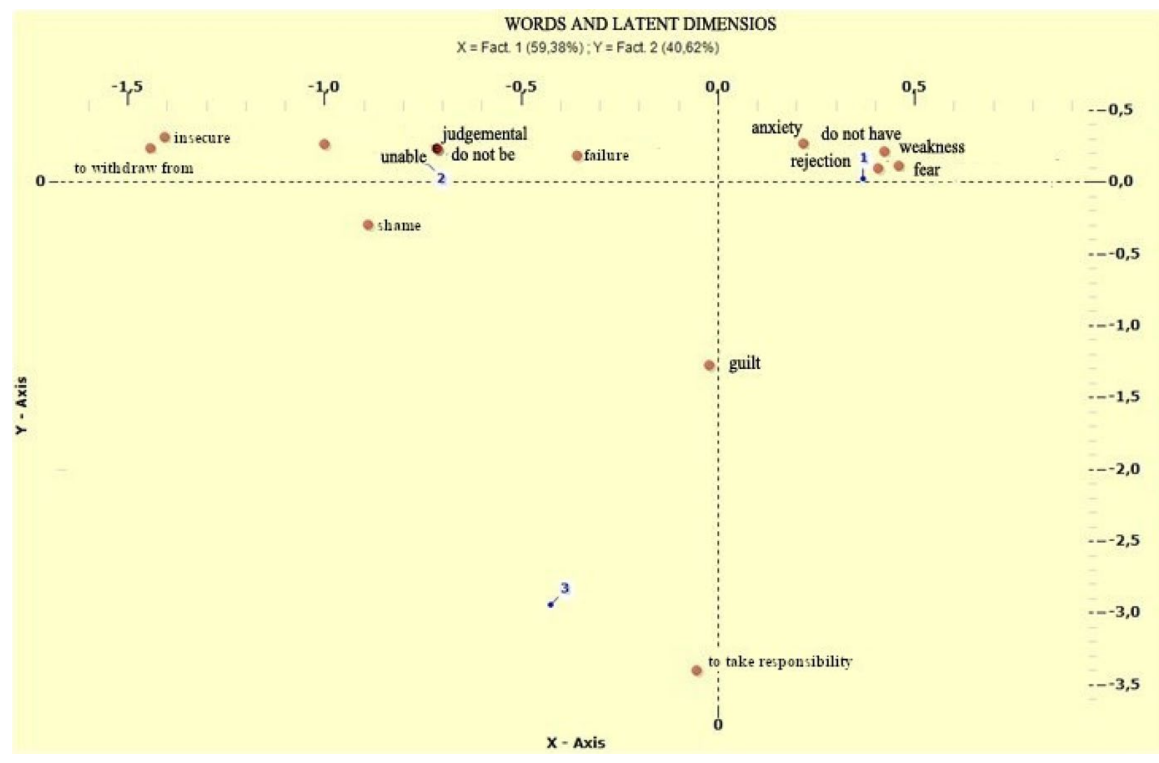

Fig. 3 Latent dimensions regarding themes

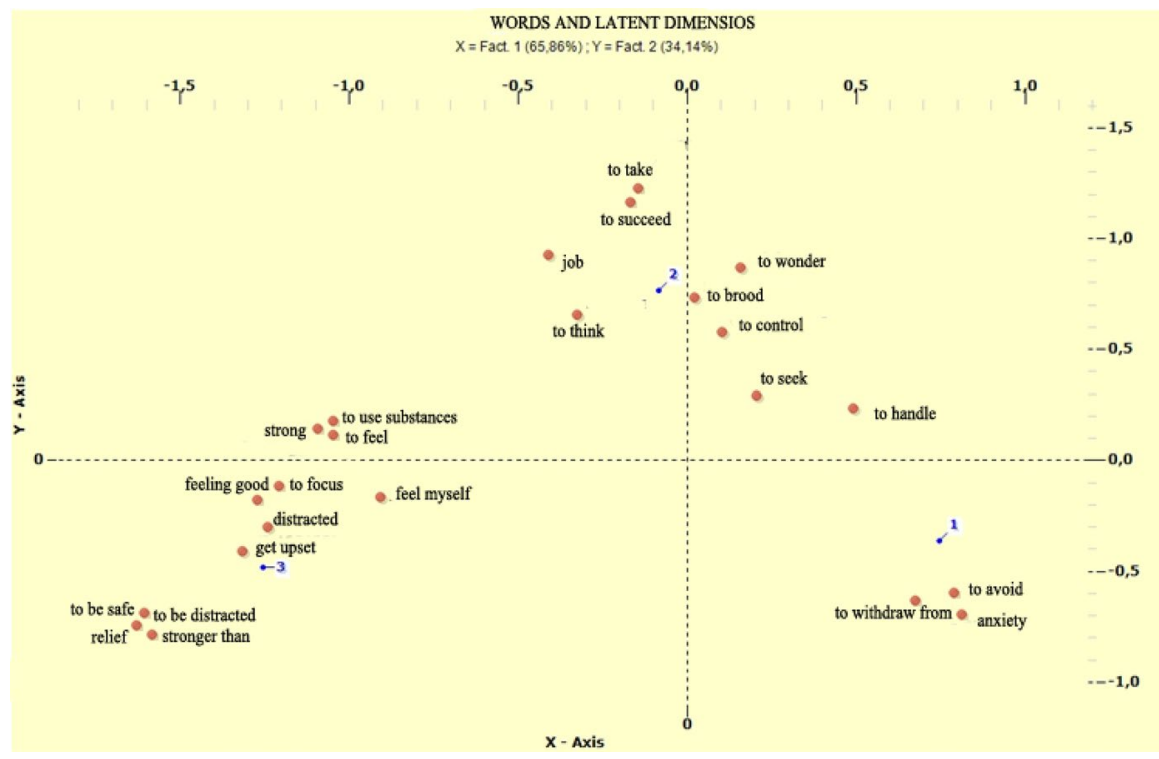

Fig. 4 Latent dimensions regarding plans

indicating a controlling coping strategy. The brown area follows, the words of which are "to lose," "to experience," "anger," "sensation," and "sadness." The brown area thus includes aspects of both depression ("sadness" and "to lose") and emotional vulnerability ("sensation" and "to experience"), roughly corresponding to the 
unloved core belief with the intrusion of an aggressive behavior ("anger"). The following (purple) area matches the words "to understand," "guilt," "to think," "to succeed," "to feel," and "to see," words suggesting a controlling behavior. The red area corresponds to words like "home," "to avoid," "situation," and "to leave," which seem to denote both looking for security and avoidance behaviors that denote both a threatened core belief and an avoidant behavior. The green area, which corresponds to words like "to be angry," "other," "people," "to be liked," "to take," and "to keep," indicates an interpersonal domain and may correspond to aggressive, controlling, and self-rewarding behaviors. Finally, in the orange area are the words "anxiety," "expectation," "inadequate," "unsuitable," "mistake," "feel," and "shame," akin to the core beliefs of inadequacy and unworthiness.

In summary, the cosine association method has provided six areas, and this is to be considered the final result as the number of categories, so we consider six instead of the hypothesized eight. However, it is also necessary to identify which six categories survived from the initial assumed eight. The answer of the cosine association in this case is indicative and not definitive because the content confirmed by the cosine association still includes all the hypothesized four CBT core self-beliefs and four CBT coping behavioral strategies. Therefore, according to the cosine association, the resulting six categories show overlapping areas that allow them to include the content of all eight assumed categories. Further explorations-implemented by the following analysis of lexical specificities-are needed in order to better define the content of the confirmed categories.

\section{Validation Process of LIBET: Top-Down Approach}

Following the conclusion that the cosine association analyses suggested a focus on six CBT variables, an analysis of lexical specificities was conducted for the purpose of identifying their semantic content. As reported in Figs. 3 and 4, this analysis confirmed three categories of CBT core beliefs (Fig. 3) and three categories of CBT coping behavioral strategies (Fig. 4).

The further and final-at least in this paper-definition of the semantic content suggested by the analysis of lexical specificities allowed us to definitely transform the six CBT categories in LIBET categories and identify a final list of three LIBET life themes, as presented in Fig. 3, and three LIBET semi-adaptive plans, as presented in Fig. 4. The clinical content and the names of the LIBET categories are reported and discussed in detail in the Subgroups within the Two Dimensions section of the Discussion. Here and in Figs. 3 and 4 we report the specific words significantly connected with semantic areas.

With regard to the CBT core beliefs that will become LIBET life themes, however, there is one result that may be partially confusing and likely signals that further replications of these analyses are needed. The result is that the visual outcome of the lexical specificities shown in Fig. 3 reports three semantic areas, represented by three numbered dots, whereas the empirical outcome reports four significant, specific word groups. 
Indeed, with regard to the CBT core beliefs of feeling threatened, the specific words (each of which was significantly connected with a semantic area, as shown by the $\chi^{2}$ tests reported in brackets next to the words) were: "danger" $\left(\chi^{2}=71.38, p<0.001\right)$, "fear" $\left(\chi^{2}=50.9, p<0.001\right)$, and "mother" $\left(\chi^{2}=32.3, p<0.001\right)$. The CBT core belief of unloved was characterized by words like "abandoned" $\left(\chi^{2}=47.56, p<0.001\right)$, "solitude" $\left(\chi^{2}=32.35\right.$, $p<0.001)$, and "sadness" $\left(\chi^{2}=17.70, p<0.01\right)$. The CBT core belief of inadequate was characterized by words like "insecure" $\left(\chi^{2}=48.51, p<0.001\right)$, "inadequate" $\left(\chi^{2}=31.05, p<0.001\right)$, "anxiety" ( $\left.\chi^{2}=17.84, p<0.01\right)$, and "to lose" $\left(\chi^{2}=16.74, p<0.01\right)$. Finally, the CBT core belief of unworthy presented words pertaining to the complex emotions of "shame" $\left(\chi^{2}=25.72, p<0.001\right)$, "guilt" $\left(\chi^{2}=21.52, p<0.001\right)$, "weak" $\left(\chi^{2}=16.62, p<0.01\right)$, "failure" $\left(\chi^{2}=12.38\right.$, $p<0.01)$, and "dumb" $\left(\chi^{2}=11.89, p<0.01\right)$.

The consequence, which will be further discussed in the Subgroups within the Two Dimensions section of the Discussion, is that there are three categories of core beliefs but four semantic areas, of which one is allocated among the other three because it does not appear in the results in Fig. 3. This scattered semantic area is that of inadequacy. The consequence is that therefore there are three semantic areas of CBT core beliefs on which the group of words related to feeling inadequate is distributed over. As will be explained in the Subgroups within the Two Dimensions section of the Discussion, there will consequently be three categories of LIBET life themes: "threatened/inadequate" (Life Theme 1), "unloved/inadequate" (Life Theme 2), and "unworthy/inadequate" (Life Theme 3).

With regard to the CBT coping behavioral strategies that will become LIBET semi-adaptive plans, fortunately the visual outcome of the lexical specificities shown in Fig. 4 and the empirical outcome are fully consistent with each other, and both report three semantic areas and groups of specific words related to three CBT coping behavioral strategies. The reduction to three of the four hypothesized coping strategies was based on the result of the semantic analysis that proposed the confluence of aggressive and self-rewarding coping strategies into a single area. As will be explained in the Subgroups within the Two Dimensions section of the Discussion, there will consequently be three categories of LIBET semi-adaptive plans: "prudential" (Semi-adaptive Plan 1), prescriptive" (Semi-adaptive Plan 2), and "immunizing” (Semi-adaptive Plan 3).

Indeed, the avoidant coping strategy was characterized by the words like "to avoid" $\left(\chi^{2}=486.6, p<0.001\right)$, "situation" $\left(\chi^{2}=37.22, p<0.001\right)$, "to leave" $\left(\chi^{2}=17.31, p<0.01\right)$, and "to sleep" $\left(\chi^{2}=13.96, p<0.01\right)$. The controlling coping strategy was characterized by words like "to seek" $\left(\chi^{2}=123.4, p<0.001\right)$, "to ruminate" $\left(\chi^{2}=78.56, p<0.001\right)$, "to control" $\left(\chi^{2}=65.33, p<0.001\right)$, and "to handle" $\left(\chi^{2}=33.93, p<0.001\right)$. Finally, the aggressive and/or self-rewarding coping strategies presented specific words like "anger" $\left(\chi^{2}=34.48, \mathrm{p}<0.001\right)$, "to smoke" $\left(\chi^{2}=26.01, \mathrm{p}<0.001\right)$, "to drink" $\left(\chi^{2}=20.94, \mathrm{p}<0.001\right)$, "food" $\left(\chi^{2}=20.94, \mathrm{p}<0.001\right)$, and "strong" $\left(\chi^{2}=17.18, p<0.01\right)$. 


\section{Discussion}

In this section we discuss the state of the validation process of the LIBET case formulation procedure and the extent to which the results can be interpreted as a validation of the general CBT diathesis-stress model. In particular, we discuss how far the arrangement of the LIBET case formulation is validated in two dimensions (i.e., life themes and semi-adaptive plans in LIBET), and their exploratory classification in subdomains, comprising three of each. We discuss the extent to which the data supporting this arrangement can be considered a validation of the general CBT diathesis-stress model and in particular of its arrangement in the two dimensions of core beliefs and coping strategies.

\section{Two-Dimensions Hypothesis in LIBET and in CBT}

The organization of the LIBET case formulation in two dimensions parallels the bidimensional arrangement into emotional vulnerabilities and coping strategies of the diathesis-stress model as typically interpreted in CBT (Beck, 1976, 2008; Beck \& Bredemeier, 2016; Clark \& Beck, 2010; Dobson et al., 2018). As mentioned in the introduction, life themes and semi-adaptive plans retain the conceptual essence of their diathesis-stress counterparts, and do not distort them by adding a developmental aspect to core self-beliefs and a process aspect to coping strategies given that we have shown in the introduction that they were implied and present in the original model. We can therefore argue that there is a correspondence between the two models, and we can assume that the results-which confirm the validity of the life themes and semi-adaptive plans arrangement in LIBET-also support the validity of the diathesis-stress model's arrangement into emotional vulnerabilities represented as core self-beliefs and coping strategies.

\section{Multidimensional Scaling}

Multidimensional scaling provides a preliminary answer in terms of the validity of constructs for the bidimensional hypothesis of both the diathesis-stress model and LIBET. Concept mapping of the results of multidimensional scaling revealed four areas interpretable as corresponding to the semantic domains of fragility, danger, and threat (red area), inadequacy, abandonment, and blame (blue area), controlling and avoiding safety behaviors (yellow area), and either dependent or aggressive behaviors (green area). This map is also compatible with the bidimensional diathesis-stress model hypothesis of core self-beliefs and coping strategies because the areas tend to show either specifically emotional or specifically behavioral contents, which can be respectively interpreted as two dimensions corresponding to those proposed in the diathesis-stress model or in the LIBET model.

In fact, in Fig. 1 the red and blue areas show content belonging to the domain of emotional vulnerability, while the other two areas present content belonging to the behavioral domain of coping strategies. Another result compatible with the 
bidimensional hypothesis is that, as shown in Fig. 1, the two $\mathrm{X}$ and $\mathrm{Y}$ axes both show a pole toward which results compatible with the emotional vulnerabilities converge (lower extreme of the $\mathrm{X}$ and extreme to the right of the $\mathrm{Y}$ ), words such as "guilt," "rejected," "solitude," and "abandonment," as well as a pole toward which results compatible with coping strategies converge (upper end of the X and extreme left of the Y), words such as "to smoke," "to drink," and "to be angry." In summary, in Fig. 1 we can see, on the right-hand side, emotional variables that may be interpreted as life themes, and on the left-hand side behavioral variables that may be interpreted as semi-adaptive plans. As noted above, this divide may confirm the bidimensionality in both the diathesis-stress model and in the LIBET case formulation arrangement.

Another way to explore the results in more depth in order to confirm this bidimensional hypothesis related to the diathesis-stress model and the LIBET case formulation, is to read the plot of Fig. 1 by using geometric figures drawn between the outermost coordinates of the representation (Greenacre, 1993). The first dimension $(\mathrm{X})$ runs closest to the profile points, and in terms of axial representation, the plot suggests a "negative" X pole (here the terms "negative" and "positive" are artifacts of the algorithm and only refer to coordinates on the graphical representation), populated by aspects related to avoidant and controlling coping strategies (words such as "to avoid," "to distract," "to keep," and "to ruminate"), while the opposite "positive" X pole is populated by aspects related to self-related vulnerability (words such as "sadness," "empty," "to feel abandoned," and "inadequacy"). In the second dimension (Y), the components present two poles: the positive extreme organized the semantic linked to rewarding and dependent behaviors (words such as "to drink," "to smoke," "food"), whereas the negative pole is related again to self-related vulnerability, characterized by words linked to feelings of guilt, solitude, being refused and a general sense of closure.

In Fig. 2, the six areas provided by the analysis of cosine associations between words as the result of the co-word analysis and the co-occurrence matrix, facilitate a mixed interpretation that is nonetheless compatible with this paper's hypothesis. The results show features that can be interpreted as subdimensions of either core beliefs or coping strategies. We can see at least three areas that are very consistent with the hypothesis. They are the pink area related to controlling behaviors ("to seek," "to control," "to handle," "to ruminate"), the red area containing content related to avoidance and withdrawal ("to leave"), and the orange area related to inadequacy ("inadequate," "unsuitable," "shame"). These areas correspond to a core belief content, such as inadequacy, and two behaviors, such as control and avoidance, once again showing separate configurations mainly related to the domain of emotional vulnerabilities or coping strategies, which are compatible with the bidimensional hypothesis.

The contents of the other areas are less internally consistent, but again show content related to emotional vulnerabilities, such as threat, unworthiness, and inadequacy, and to coping strategies, such as avoidant, controlling, and reactive behaviors. In summary, although these results cannot be regarded as conclusive confirmation of the bidimensional hypothesis, they do distinguish emotional vulnerabilities and coping strategies and are therefore compatible with the bidimensional hypothesis. 


\section{Subgroups Within the Two Dimensions}

The analyses presented in Figs. 3 and 4 explore conceptual areas that can be interpreted as subdimensions within the two dimensions. The results of the analysis of lexical specificities represented in Figs. 3 and 4 suggest six clusters that show contents which can be classified as the subdimensions of life themes and semi-adaptive plans.

The clusters can be interpreted in clinical terms comparing the verbal content of each cluster to the emotional vulnerability states described in the clinical and scientific literature. Figure 3 suggests a preliminary list of three categories of life themes.

The first cluster may correspond to a vulnerability state of freezing/panic (Herman, 1992; Ogden et al., 2006; van der Kolk, 1996), which we have linked to the life theme of feeling threatened/inadequate, or the need to possess a protected place of personal safety, nourishment and care (Siegel, 1999). The absence of security can lead to a self-perception of endlessness and disorganization (Ogden et al., 2006).

A second cluster refers to sadness and depression (Bifulco et al., 2006; Huprich, 2003; Kiernan \& Huerta, 2008), linked to a life theme of feeling unloved/inadequate, in which, although a partially protective environment may be present, either the exploratory needs of the subject are hampered or everything is provided in a cold atmosphere of emotional deprivation, dismissing affectivity, and in which bodily contact is rare and clumsy (Bosquet \& Egeland, 2006; Woodruff-Borden et al., 2002).

The third cluster primarily concerns shame and guilt (Brewin et al., 1992; Huprich, 2003; Irons et al., 2006; Kawamura et al., 2001; Vieth \& Trull, 1999), linked to a life theme of feeling unworthy/inadequate, where there is a severely critical, controlling and oppressive relational style and rules are experienced and transmitted in an oppressive, moralistic, guilty and punitive manner.

Figure 4 suggests a preliminary list of three categories of semi-adaptive plans. The first cluster corresponds to the prudential plan, in which people tend to avoid aversive and threatening stimulations. The consequence is a failure to develop exploratory and constructive aspects of existence (Barlow, 2002; Blalock \& Joiner, 2000).

The second cluster is the prescriptive plan, in which the individual steadily attempts to control, prevent, or resolve any adverse stimuli. This preventive plan can be manifested in either worrying about problems and relationships, or in compulsory controlling behaviors (Barlow, 2002; Moulding \& Kyrios, 2006; Ruggiero et al., 2012; Sassaroli et al., 2008; Shafran et al., 2002).

The third cluster pertains to the immunizing plan, in which the subject seeks to exclude from their consciousness any painful state through emotional manipulation of internal state, whether by (1) involving themselves in intensely expressed interpersonal states of anger and aggressivity or (2) either self-rewarding and exciting or reducing consciousness (e.g., taking exciting or sedative substances). These plans are related to intentional states of anger and/or desire (Critchfield et al., 2008; Di Giuseppe \& Tafrate, 2001; Mansueto et al., 2019; Martin \& Dahlen, 2005; Spada et al., 2013). 


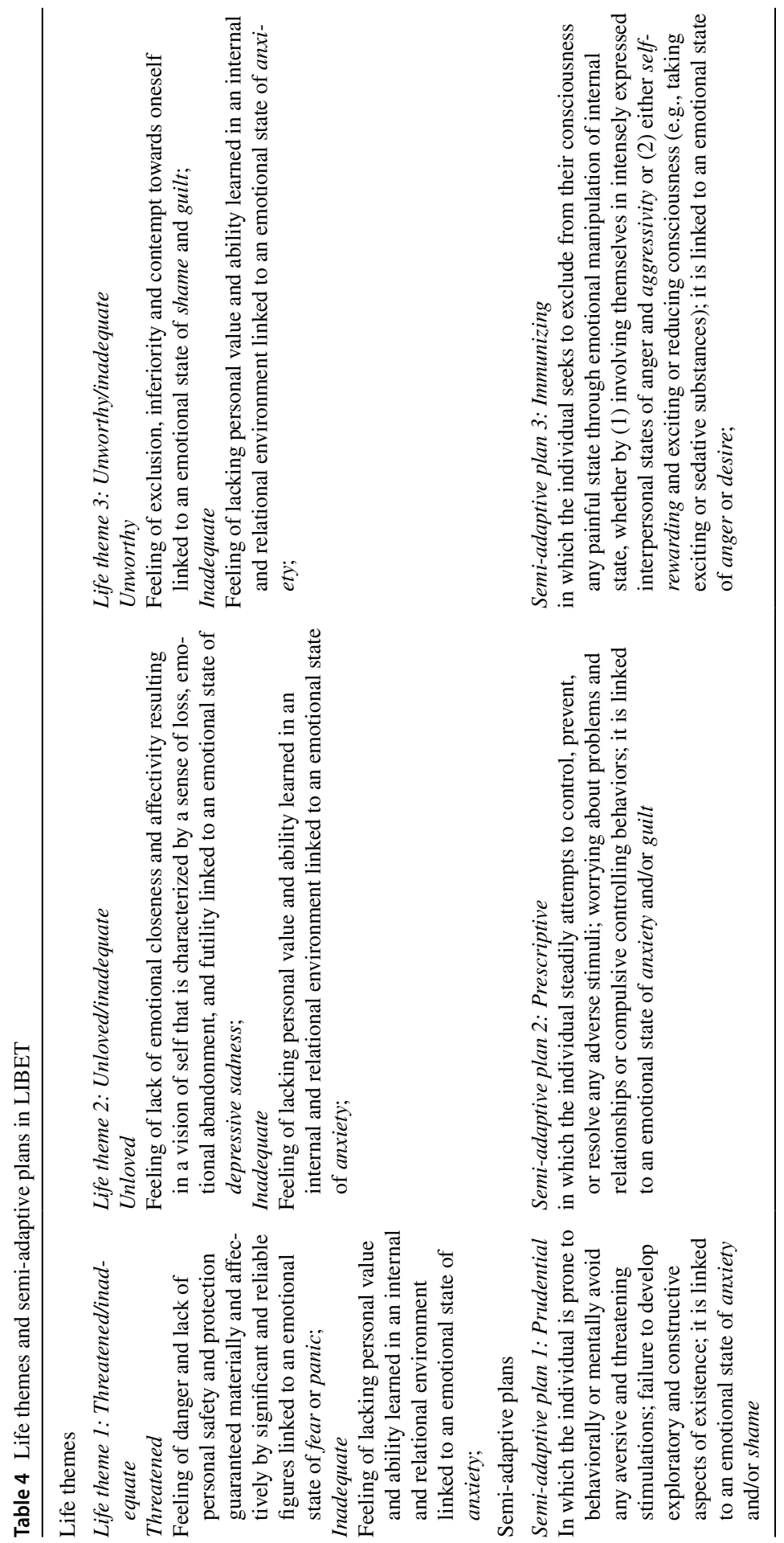


Table 4 reports and describes the preliminary categories of Life themes and Semi-adaptive plans in LIBET.

\section{Clinical Implications}

LIBET provides a synthetic conceptualization based on individual concrete problem situations that are then included in a general formulation of the case in broader terms: the life themes and semi-adaptive plans. In this way the LIBET conceptualization aims to bring together both REBT's ability to focus on specific problems related to defined situations and Beck's ability to provide a broad view of the case. The LIBET also includes problematic situations from the past, providing a conceptualization of life history as in the constructivist orientation. The LIBET articulates the formulation of the case on the two axes of the CBT diathesis-stress model of vulnerability to emotional disorders, that is, the predisposing factors called life themes (the patient's emotional vulnerabilities perceived in terms of core beliefs) and the maintenance factors called semi-adaptive plans (their coping strategies) that render a disorder chronic.

Coping strategies are the final evolution of the maintenance processes already outlined in the classical cognitive model in terms of the fear of fear circle by Beck (Beck et al., 1985) and even more sharply by Ellis with his seminal concept of secondary ABC (DiGiuseppe et al., 2014, pp. 64-65) as well as in constructive approaches (Guidano \& Liotti, 1983; Mahoney, 2003; Sassaroli et al., 2005). On the other hand, predisposing factors formalize those developmental aspects that have also been cultivated in CBT. In this way, the case formulation of LIBET allows one: (a) to assess dysfunctional and transdiagnostic processes of personality functioning independently of the acute phase of emotional disorders; and (b) to explain the interaction between premorbid vulnerability and emotional/behavior disorders, as well as its maintaining dysfunctional coping cycles. In conclusion, the LIBET model may allow the therapist: (1) to move throughout the treatment following a flexible but constant and transdiagnostic conceptualization, using a limited number of variables (transdiagnostic processes) as indicators of flexible functioning; and (2) to plan the therapeutic intervention taking into account both the stage of the symptoms and the map of personality vulnerabilities in terms of painful themes and semi-adaptive plans of mental activity regulation, as well as their interaction.

While Judith Beck's CCD formulation led to a single intervention, namely CBT questioning and behavioral exposure, LIBET aims to provide a range of indicators that allow for clinical choice. While the single technical choice of CBT questioning corresponded to a less historically diverse scenario, such as the CBT of the 1980s, today we are witnessing an increasingly varied technical repertoire that is expanding into both the exploration of personal life history and CBT process-based interventions. Nevertheless, such increased richness is also a risk, and therefore today the formulation of a clinical case must not only be able to provide evidence of internal validity, but also indications for therapeutic choice, which no longer operate in just one way. Consequently, further analyses must involve not only the convergent and divergent validity of LIBET in order to further confirm validity, but above all 
undertake validity analysis of the indicators for the psychotherapeutic project and planning treatment. The three themes and three plans of LIBET aim to serve this purpose. At present these are not real indicators, but mere heuristics that can be used on the basis of clinical experience. For example, the themes unloved/inadequate and unworthy/inadequate may justify interventions in the developmental history (presumably cold and distant for unloved/inadequate, and critical for unworthy/inadequate), or the classic CBT intervention of the verbal reattribution and procedural acceptance. The prudential and prescriptive plans seem to suggest behavioral interventions of reactivation and exposure alongside the aforementioned classic CBT intervention of verbal reattribution of beliefs that support the feared consequences. Finally, the immunization plan and the threat theme open up the field of skills training and emotional tolerance interventions.

\section{Limitations and Future Directions}

The major limitation of this study is that it was performed on a single clinical sample of patients with anxiety and mood disorders. So far, LIBET has not been tested on other disorders of psychotherapeutic interest, such as personality disorders. The results of this study confirming the diathesis-stress model of CBT and validating the LIBET case formulation procedure can therefore currently only be considered valid for this clinical area. On the other hand, we note that the CBT diathesis-stress model was designed by Beck for depression and anxiety disorders. The practical reason for this choice is that our research group started the validation of LIBET because it works in collaboration with a group of CBT-trained therapists working with patients with this type of diagnosis. Of course, the next steps include the application of the LIBET model to other diagnoses, starting with personality disorders. It is possible that in different samples the structure of LIBET may change. In particular, it is possible that the semi-adaptive immunizing plan differs in subgroups. Its nature is already hybrid, as there are either self-rewarding or aggressive behavior types.

Another possible limitation of this study is that we have not yet included in the model reported in Table 1 cognitive models that do not specifically focus on a selfbelief, such as the intolerance of uncertainty outlined by Michel Dugas (Dugas et al., 2004) or the REBT model by Albert Ellis (DiGiuseppe et al., 2014; Ellis \& Grieger, 1986). This is because these models focus more on other components of the psychopathological mechanism, components that make them more akin to "third wave" processes than to cognitive contents such as self-beliefs. These processes will be included in the above-mentioned third level of LIBET, which will be presented and validated in the next publication.

Important aspects of reliability and validity remain to be measured; however, we can report here that the inter-rater reliability of the LIBET interview version validated in this study was measured on 30 patients evaluated twice by two raters, AB and $\mathrm{CR}$, in order to calculate the $\mathrm{K}$ Cohen index, which was equal to 0.9. Another direction for development is the construction — already started—of a self-administered measurement of LIBET that makes its evaluation more agile. 
The development of LIBET is just at its beginning, and many steps remain to be taken. We have not yet presented data from the third level of evaluating LIBET, which is to be added to the themes and plans: that of the processes. Once added, LIBET will contain evolutionary aspects (in themes), standard cognitive aspects (in themes and plans) and process aspects (in processes) integrating constructivism, standard CBT, and the "third wave". Despite these limitations, the LIBET procedure holds considerable promise in helping to validate the CBT diathesis-stress model.

Funding This research received no specific grant from any funding agency.

\section{Declarations}

Conflict of interest The authors report no conflict of interest.

Ethical Approval Ethical approval for the study was granted by the Sigmund Freud University Ethics Commission and all participants provided written informed consent.

Open Access This article is licensed under a Creative Commons Attribution 4.0 International License, which permits use, sharing, adaptation, distribution and reproduction in any medium or format, as long as you give appropriate credit to the original author(s) and the source, provide a link to the Creative Commons licence, and indicate if changes were made. The images or other third party material in this article are included in the article's Creative Commons licence, unless indicated otherwise in a credit line to the material. If material is not included in the article's Creative Commons licence and your intended use is not permitted by statutory regulation or exceeds the permitted use, you will need to obtain permission directly from the copyright holder. To view a copy of this licence, visit http://creativecommons.org/licen ses/by/4.0/.

\section{References}

Allen, A., Kannis-Dymand, L., \& Katsikitis, M. (2017). Problematic internet pornography use: The role of craving, desire thinking, and metacognition. Addictive Behaviors, 70, 65-71.

American Psychiatric Association. (2013). Diagnostic and statistical manual of mental disorders (5th ed.). Arlington, VA: American Psychiatric Publishing, 2013. Italian edition (2014): Manuale diagnostico e statistico dei disturbi mentali. Milano, Italy: Raffaello Cortina.

Apparigliato, M., Ruggiero, G. M., \& Sassaroli, S. (2007). Il Perceived criticism inventory (PCI): Un nuovo strumento di valutazione del criticismo genitoriale [the perceived criticism inventory (PCI): A new tool for evaluating parental criticism]. Psicoterapia Cognitiva e Comportamentale, 13, $275-300$.

Bandura, A. (1977). Self-efficacy: Toward a unifying theory of behavioral change. Psychological Review, $84,191-215$.

Bandura, A. (1988). Self-efficacy conception of anxiety. Anxiety Research, 1, 77-98.

Bannister, D., \& Fransella, F. (1971). Inquiring man: The psychology of personal constructs (3rd ed.). Penguin.

Bannister, D., \& Mair, J. M. M. (1968). The evaluation of personal constructs. Academic Press.

Barlow, D. H. (2002). Anxiety and its disorders: The nature and treatment of anxiety and panic. Guilford Press.

Beck, A. T. (1976). Cognitive therapies and emotional disorders. International Universities Press.

Beck, A. T. (1996). Beyond belief: A theory of modes, personality, and psychopathology. In P. M. Salkovskis (Ed.), Frontiers of cognitive therapy (pp. 1-26). Guilford Press. 
Beck, A. T. (2008). The evolution of the cognitive model of depression and its neurobiological correlates. American Journal of Psychiatry, 165(8), 969-977.

Beck, A. T., \& Bredemeier, K. (2016). A unified model of depression: Integrating clinical, cognitive, biological, and evolutionary perspectives. Clinical Psychological Science, 4, 596-619.

Beck, A. T., Emery, G., \& Greenberg, R. L. (1985). Anxiety disorders and phobias: A cognitive perspective. New York, NY: Basic Books.

Beck, A. T., Rush, A. J., Shaw, B. F., \& Emery, G. (1979). Cognitive therapy of depression. Guilford Press.

Beck, A. T., Steer, R. A., Ball, R., \& Ranieri, W. (1996a). Comparison of beck depression inventories-IA and -II in psychiatric outpatients. Journal of Personality Assessment., 67, 588-597.

Beck, A. T., Steer, R. A., \& Brown, G. K. (1996b). Manual for the beck depression inventory-II. Psychological Corporation.

Beck, A. T., Ward, C. H., Mendelson, M., Mock, J., \& Erbaugh, J. (1961). An inventory for measuring depression. Archives of General Psychiatry, 4, 561-571.

Beck, J. S. (2011). Cognitive behavior therapy: Basic and beyond. Guilford Publications.

Beevers, C. G., Wenzlaff, R. M., Hayes, A. M., \& Scott, W. D. (1999). Depression and the ironic effects of thought suppression: Therapeutic strategies for improving mental control. Clinical Psychology: Science and Practice, 6, 133-148.

Bieling, P. J., \& Kuyken, W. (2003). Is cognitive case formulation science or science fiction? Clinical Psychology: Science and Practice, 10(1), 52-69.

Bifulco, A., Kwon, J., Jacobs, C., Moran, P. M., \& Bunn, A. (2006). Adult attachment style as mediator between childhood neglect/abuse and adult depression and anxiety. Social Psychiatry and Psychiatric Epidemiology, 41, 796-805.

Blalock, J. A., \& Joiner, T. E. (2000). Interaction of cognitive avoidance coping and stress in predicting depression/anxiety. Cognitive Therapy and Research, 24, 47-65.

Bolden, R., \& Moscarola, J. (2000). Bridging the quantitative-qualitative divide. Social Science Computer Review, 18, 450-460.

Borg, I., Groenen, P. J. F., \& Mair, P. (2013). Applied multidimensional scaling. Springer Statistics.

Borroni, A., \& Fossati, S. (2017). Intervista clinica strutturata per i disturbi del DSM-5: Versione per il Clinico [Structured Clinical Interview for DSM-5 Disorders: Clinician Version]. Raffaello Cortina.

Bosquet, M., \& Egeland, B. (2006). The development and maintenance of anxiety symptoms from infancy through adolescence in a longitudinal sample. Development and Psychopathology, 18, 517-550.

Brewin, C. R., Firth-Cozens, J., Furnham, A., \& McManus, C. (1992). Self-criticism in adulthood and recalled childhood experience. Journal of Abnormal Psychology, 101(3), 561.

Bruch, M. H. (2015). Beyond diagnosis: Case formulation in cognitive behavioural therapy. John Wiley \& Sons Ltd.

Bruch, M. H. (1998). Cognitive-behavioral case formulation. In E. Sanavio (Ed.), Behavior and cognitive therapy today: Essays in honor of Hans J. Eysenck (pp. 31-48). Pergamon.

Bruner, J. (1973). Going beyond the information given. Norton.

Butler, G. (1998). Clinical formulation. In A. S. Bellack \& M. Hersen (Eds.), Comprehensive clinical psychology (pp. 1-24). Pergamon Press.

Button, E. (1985). Eating disorders: A quest for control? In E. Button (Ed.), Personal construct theory and mental health (pp. 153-168). Croom Helm.

Button, E. (2005). Eating disorders. In D. Winter \& L. L. Viney (Eds.), Personal construct psychotherapy (pp. 198-211). Whurr Publishers.

Capo, R., \& Mancini, F. (2008). Scopi terminali, temi di vita e psicopatologia [Terminal goals, life themes and psychopathology]. In C. Perdighe \& F. Mancini (Eds.), Elementi di psicoterapia cognitiva: II edizione [Elements of cognitive psychotherapy: II edition] (pp. 39-68). Fioriti.

Capo, R., Mancini, F., \& Barcaccia, B. (2010). Temi di vita e psicopatologia [Life themes and psychopathology]. In A. Pacciolla \& F. Mancini (Eds.), Cognitivismo Esistenziale: Dal significato del sintomo al significato della vita [Existential Cognitivism: From the meaning of the symptom to the meaning of life] (pp. 202-226). Franco Angeli.

Caselli, G., \& Spada, M. M. (2015). Desire thinking: What is it and what drives it? Addictive Behaviors, 44, 71-79.

Chadwick, P., Williams, C., \& Mackenzie, J. (2003). Impact of case formulation in cognitive behaviour therapy for psychosis. Behaviour Research and Therapy, 41(6), 671-680. 
Christensen, A., Jacobson, N. S., \& Babcock, J. C. (1995). Integrative behavioral couple therapy. In N. S. Jacobson \& A. S. Gurman (Eds.), Clinical handbook of couples therapy (pp. 31-64). Guilford Press.

Clark, D. A., \& Beck, A. T. (2010). Cognitive therapy of anxiety disorders: science and practice. Guilford Press.

Clark, D. A., Beck, A. T., \& Alford, B. A. (1999). Scientific foundations of cognitive theory and therapy of depression. John Wiley \& Sons Ltd.

Critchfield, K. L., Levy, K. N., Clarkin, J. F., \& Kernberg, O. F. (2008). The relational context of aggression in borderline personality disorder: Using adult attachment style to predict forms of hostility. Journal of Clinical Psychology, 64, 67-82.

Csikszentmihalyi, M., \& Beattie, O. V. (1979). Life themes: A theoretical and empirical exploration of their origins and effects. Journal of Humanistic Psychology, 19, 45-63.

David, D., Freeman, A., \& DiGiuseppe, R. (2005). Rational and irrational beliefs: Implications for mechanisms of change and practice in psychotherapy. In D. David, S. J. Lynn, \& A. Ellis (Eds.), Rational and irrational beliefs: Research, theory and clinical practice (pp. 195-217). Oxford University Press.

Dierker, L. C., Merikangas, K. R., \& Szatmari, P. (1999). Influence of parental concordance for psychiatric disorders on psychopathology in offspring. Journal of the American Academy of Child \& Adolescent Psychiatry, 38(3), 280-288.

DiGiuseppe, R., \& Tafrate, R. C. (2001). A comprehensive treatment model for anger disorders. Psychotherapy: Theory Research, Practice, Training, 38, 262-271.

DiGiuseppe, R., \& Tafrate, R. C. (2007). Understanding anger disorders. Oxford: Oxford University Press.

DiGiuseppe, R., Doyle, K. A., Dryden, W., \& Backx, W. (2014). A Practioner's guide to rational emotive behavior therapy. Oxford University Press.

Di Fini, G., \& Veglia, F. (2019). Life themes and attachment system in the narrative self-construction: Direct and indirect indicators. Frontiers in Psychology, 10, 1393-1406.

Dimaggio, G., Semerari, A., Carcione, A., Nicolò, G., \& Procacci, M. (2007). Psychotherapy of personality disorders: Metacognition, states of mind and interpersonal cycles. Routledge.

Dobson, K. S., \& Khatri, N. (2000). Cognitive therapy: Looking backward, looking forward. Journal of Clinical Psychology, 56(7), 907-923.

Dobson, K. S., Poole, J. C., \& Beck, J. S. (2018). The fundamental cognitive model. In R. L. Lehay (Ed.), Science and practice in cognitive therapy: Foundations, mechanisms, and applications (pp. 29-47). Guilford Publications.

Dodet, M. (2010). Self meaning e tema di vita [Self meaning and life theme]. In A. Pacciolla \& F. Mancini (Eds.), Cognitivismo Esistenziale: Dal significato del sintomo al significato della vita [Existential Cognitivism: From the meaning of the symptom to the meaning of life] (pp. 148-169). Franco Angeli.

Dragan, M. (2015). Difficulties in emotion regulation and problem drinking in young women: The mediating effect of metacognitions about alcohol use. Addictive Behaviors, 48, 30-35.

Dugas, M. J., Buhr, K., \& Ladouceur, R. (2004). The role of intolerance of uncertainty in etiology and maintenance. In R. G. Heimberg, C. L. Turk, \& D. S. Mennin (Eds.), Generalized anxiety disorder: Advances in research and practice (pp. 143-163). The Guilford Press.

Eells, T. D. (2007). Handbook of psychotherapy case formulation. Guilford Press.

Eells, T. D. (2011). Handbook of psychotherapy case formulation (2nd ed.). Guilford Press.

Eells, T. D. (2015). Psychotherapy case formulation. American Psychological Association.

Ellis, A. (1962). Reason and emotion in psychotherapy. Stuart.

Ellis, A., \& Grieger, R. M. (Eds.). (1986). Handbook of rational-emotive therapy. Springer.

Erikson, E. (1950). Childhood and society. Norton and Company.

Evans, J., \& Parry, G. (1996). The impact of reformulation in cognitive-analytic therapy with difficulttohelp clients. Clinical Psychology and Psychotherapy, 3, 109-117.

Feixas, G., \& Miró, M. (1993). Aproximaciones ala psicoterapia una introducción a los tratamientos psicológicos [Approaches to psychotherapy an introduction to psychological treatments]. Paidós.

Feng, F., Ming, L. I., \& Ruofan, L. I. (2017). Mediating effect of feeling of inadequacy on relationship between self-consistency and anxiety in medical students. Chinese Journal of Behavioral Medicine and Brain Science, 26(5), 462-466. 
First, M. B., Williams, J. B. W., Benjamin, L. S., \& Spitzer, R. L. (2015). User's Guide for the SCID5-PD (Structured clinical interview for DSM-5 personality disorder). American Psychiatric Association.

First, M. B., Williams, J. B. W., Karg, R. S., \& Spitzer, R. L. (2015). Structured clinical interview for DSM-5 disorders, clinician version (SCID-5-CV). American Psychiatric Association.

Flitcroft, A., James, I. A., Freeston, M., \& Wood-Mitchell, A. (2007). Determining what is important in a good formulation. Behavioural and Cognitive Psychotherapy, 35(3), 325-333.

Frankl, V. (2006). Man's search for meaning. An Introduction to Logotherapy. Originally published in 1946. Beacon Press.

Fyer, A. J., Mannuzza, S., Chapman, T. F., Liebowitz, M. R., \& Klein, D. F. (1993). A direct interview family study of social phobia. Archives of General Psychiatry, 50, 286-293.

Ghaderi, A. (2006). Does individualization matter? A randomized trial of standardized (focused) versus individualized (broad) cognitive behavior therapy for bulimia nervosa. Behavior Research and Therapy, 44, 273-288.

Ghisi, M., Flebus, G. B., Montano, A., Sanavio, E., \& Sica, C. (2006). Beck depression inventory-second edition. Adattamento italiano: Manuale. Organizzazioni Speciali.

Greenacre, M. J. (1993). Correspondence analysis in practice. Academic Press.

Griskevicius, V., Shiota, M. N., \& Neufeld, S. (2010). Influence of different positive emotions on persuasion processing: A functional evolutionary approach. Emotion, 10, 190-206.

Guidano, V. F. (1987). Complexity of the self. Guilford Press.

Guidano, V. F. (1991). The self in process: Toward a post-rationalist cognitive therapy. Guilford Press.

Guidano, V. F., \& Liotti, G. (1983). Cognitive processes and emotional disorders: A structural approach to psychotherapy. Guilford Press.

Guiraud, P. (1960). Problèmes et méthodes de la statistique linguistique [Problems and methods of the linguistic statistics]. Presses Universitaires de France.

Hayes, S. C., \& Hoffman, S. G. (2018). Process-based CBT the science and core clinical competencies of cognitive behavioral therapy. Context Press.

Hayes, S. C., \& Strosahl, K. D. (2004). A practical guide to acceptance and commitment therapy. Guildford Press.

Herman, J. (1992). Trauma and recovery: The aftermath of violence-from domestic abuse to political terror. Perseus.

Hermans, H. J. M. (1996a). Opposites in a dialogical self: Constructs as characters. Journal of Constructivist Psychology, 9, 1-26.

Hermans, H. J. M. (1996b). Voicing the self: From information processing to dialogical interchange. Psychological Bulletin, 119, 31-50.

Hermans, H. J. M. (2002). The dialogical self as society of mind: Introduction. Theory \& Psychology, 12, $147-160$.

Hinkle, D. N. (1965). The Change of personal constructs from the viewpoint of a theory of construct implications. Unpublished $\mathrm{PhD}$ dissertation, Columbus, $\mathrm{OH}$ : Ohio State University.

Hirshfeld, D. R., Biederman, J., Brody, L., Faraone, S. V., \& Rosenbaum, J. F. (1997). Associations between expressed emotion and child behavioral inhibition and psychopathology: A pilot study. Journal of the American Academy of Child \& Adolescent Psychiatry, 36, 205-213.

Hollon, S. D., DeRubeis, R. J., Andrews, P. W., \& Anderson Thomson, J. (2020). Cognitive Therapy in the treatment and prevention of depression: A fifty-year retrospective with an evolutionary coda. Cognitive Therapy and Research. https://doi.org/10.1007/s10608-020-10132-1

Hoyer, J., Becker, E. S., \& Roth, W. T. (2001). Characteristics of worry in GAD patients, social phobics, and controls. Depression and Anxiety, 13(2), 89-96.

Huprich, S. K. (2003). Depressive personality and its relationship to depressed mood, interpersonal loss, negative parental perceptions, and perfectionism. Journal of Nervous \& Mental Disease, 191, 73-79.

Irons, C., Gilbert, P., Baldwin, M. W., Baccus, J. R., \& Palmer, M. (2006). Parental recall, attachment relating and self-attacking/self-reassurance: Their relationship with depression. British Journal of Medical Psychology, 45, 297-308.

Jaspers, K. (1971). Philosophy of existence. University of Pennsylvania Press.

Kahneman, D., \& Frederick, S. (2002). Representativeness revisited: Attribute substitution in intuitive judgment. In T. Gilovich, D. Griffin, \& D. Kahneman (Eds.), Heuristics and biases (pp. 49-81). Cambridge University Press.

Kanter, J. W., Bush, A. M., \& Rush, L. C. (2009). Behavioral activation. Routledge. 
Kawamura, K. Y., Frost, R. O., \& Harmatz, M. G. (2001). The relationship of perceived parenting styles to perfectionism. Personality and Individual Differences, 32, 317-327.

Kelly, G. A. (1955). The Psychology of Personal Constructs: Vol 1 and 2. New York, NY, USA: Norton.

Kendjelic, E. M., \& Eells, T. D. (2007). Generic psychotherapy case formulation training improves formulation quality. Psychotherapy Theory, Research, Practice, Training, 44(1), 66.

Kiernan, K. E., \& Huerta, M. C. (2008). Economic deprivation, maternal depression, parenting and children's cognitive and emotional development in early childhood. The British Journal of Sociology, 59, 783-806.

Kohlenberg, R. J., \& Tsai, M. (1991). Functional analytic psychotherapy: Creating intense and curative therapeutic relationships. Plenum Press.

Kohlenberg, R. J., \& Tsai, M. (1997). Functionally enhanced cognitive therapy. University of Washington, FECT Treatment Project.

Kohut, H. (1977). The restoration of the self. International Universities Press.

Kruskal, J. B., Wish, M., \& Uslaner, E. M. (2006). Multidimensional scaling. Sage Publications.

Kuyken, W. (2006). Evidence-based case formulation: Is the emperor clothed? In N. Tarrier (Ed.), Case formulation in cognitive behaviour therapy. The treatment of challenging and complex cases (pp. 28-51). Routledge.

Kuyken, W., Fothergill, C. D., Musa, M., \& Chadwick, P. (2005). The reliability and quality of cognitive case formulation. Behaviour Research and Therapy, 43, 1187-1201.

Kuyken, W., Kurzer, N., DeRubeis, R. J., Beck, A. T., \& Brown, G. K. (2001). Response to cognitive therapy in depression: The role of maladaptive beliefs and personality disorders. Journal of Consulting and Clinical Psychology, 69, 560.

Kuyken, W., Padesky, C. A., \& Dudley, R. (2008). The science and practice of case conceptualization. Behavioural and Cognitive Psychotherapy, 36(6), 757-768.

Lancia, F. (2008). Word co-occurrence and similarity in meaning. Some methodological issues. In S. Salvatore \& J. Valsiner (Eds.), Mind as infinite dimensionality (pp. 1-39). Edizioni Carlo Amore.

Layard, R., \& Clark, D. M. (2014). Thrive: The power of evidence-based psychological therapies. Penguin.

Linehan, M. M. (1993). Cognitive-behavioral treatment of borderline personality disorder. Guilford Press.

Lorenzini, R., \& Sassaroli, S. (1995). Attaccamento, conoscenza e disturbi di personalità [Attachment, knowledge and personality disorders]. Raffaello Cortina Editore.

Lund, K., \& Burgess, C. (1996). Producing high dimensional semantic spaces from lexical co-occurrence. Behavior Research Methods, Instruments, \& Computers, 28(2), 203-208.

Maheu, F. S., Dozier, M., Guyer, A. E., Mandell, D., Peloso, E., Poeth, K., \& Ernst, M. (2010). A preliminary study of medial temporal lobe function in youths with a history of caregiver deprivation and emotional neglect. Cognitive, Affective, \& Behavioral Neuroscience, 10(1), 34-49.

Mahoney, M. J. (1974). Cognition and behavior modification. Ballinger.

Mahoney, M. J. (1991). Human change process. Basic Books.

Mahoney, M. J. (2003). Constructive psychotherapy: A practical guide. Guilford Publications.

Mansueto, G., Martino, F., Palmieri, S., Scaini, S., Ruggiero, G. M., Sassaroli, S., \& Caselli, G. (2019). Desire Thinking across addictive behaviours: A systematic review and meta-analysis. Addictive behaviors, 98, 106018.

Markus, H. (1977). Self-schemata and processing information about the self. Journal of Personality and Social Psychology, 35, 63-78.

Martell, C. R., Addis, M. E., \& Jacobson, N. S. (2001). Depression in context: Strategies for guided action. Norton.

Martin, J. W., \& Sloman, S. A. (2013). Refining the dual-system theory of choice. Journal of Consumer Psychology, 23, 552-555.

Martin, R. C., \& Dahlen, E. R. (2005). Cognitive emotion regulation in the prediction of depression, anxiety, stress, and anger. Personality and Individual Differences, 39, 1249-1260.

May, J., Andrade, J., Panabokke, N., \& Kavanagh, D. (2004). Images of desire: Cognitive models of craving. Memory, 12(4), 447-461.

McCullough, J. P., Jr., \& Goldfried, M. R. (1999). Treatment for chronic depression: Cognitive behavioral analysis system of psychotherapy $(C B A S P)$. Guilford Press.

Meichenbaum, D. H. (1977). Cognitive behavior modification. Plenum Press.

Mineka, S., \& Zinbarg, R. (1996). Conditioning and ethological models of anxiety disorders: Stress-indynamic-context anxiety models. In D. A. Hope (Ed.), Current theory and research in motivation 
Nebraska symposium on motivation, 1995: Perspectives on anxiety, panic, and fear (Vol. 43, pp. 135-210). University of Nebraska Press.

Mogg, K., \& Bradley, B. P. (2016). Anxiety and attention to threat: Cognitive mechanisms and treatment with attention bias modification. Behaviour Research and Therapy, 87, 76-108.

Möller, H. J., Bandelow, B., Volz, H. P., Barnikol, U. B., Seifritz, E., \& Kasper, S. (2016). The relevance of "mixed anxiety and depression" as a diagnostic category in clinical practice. European Archives of Psychiatry and Clinical Neuroscience, 266, 725-736.

Montano A, \& Flebus, G.B. (2006). Presentazione del Beck Depression Inventory-Seconda Edizione (BDI-II): conferma della struttura bifattoriale in un campione di popolazione italiana [Presentation of the Beck Depression Inventory-Second Edition (BDI-II): confirmation of the bifactorial structure in a Italian population sample]. Psicoterapia Cognitiva e Comportamentale, 12, 67-82.

Moulding, R., \& Kyrios, M. (2006). Anxiety disorders and control related beliefs: The example of obsessive-compulsive disorder (OCD). Clinical Psychology Review, 26, 573-583.

Mugavin, M. E. (2008). Multidimensional scaling: A brief overview. Nursing Research, 57, 64-68.

Mumma, G. H., \& Mooney, S. R. (2007). Incremental validity of cognitions in a clinical case formulation: An intraindividual test in a case example. Journal of Psychopathology and Behavioral Assessment, 29(1), 17-28.

Mumma, G. H., \& Smith, J. L. (2001). Cognitive-behavioral-interpersonal scenarios: Interformulator reliability and convergent validity. Journal of Psychopathology and Behavioral Assessment, 23(4), 203-221.

Needleman, L. D. (1999). Cognitive case conceptualization: A guidebook for practitioners. Routledge.

Neimeyer, R. A. (2009). Constructivist psychotherapy. Distinctive Features. Routledge.

Neimeyer, R. A., \& Mahoney, M. J. (Eds.). (1995). Constructivism in psychotherapy. APA Press.

Neisser, U. (1967). Cognitive psychology. Prentice-Hall.

Nelson-Gray, R. O., Herbert, J. D., Herbert, D. L., Sigmon, S. T., \& Brannon, S. E. (1989). Effectiveness of matched, mismatched, and package treatments of depression. Journal of Behavior Therapy and Experimental Psychiatry, 20, 281-294.

Nestor, P. G., \& Schutt, R. K. (2014). Research methods in psychology: Investigating human behavior (2nd ed.). Sage Publications.

Ogden, P., Minton, K., \& Pain, C. (2006). Trauma and the body: A sensorimotor approach to psychotherapy. Norton.

Pain, C. M., Chadwick, P., \& Abba, N. (2008). Clients' experience of case formulation in cognitive behaviour therapy for psychosis. British Journal of Clinical Psychology, 47, 127-138.

Pallanti, S., Grassi, G., Cantisani, A., Sarrecchia, E., \& Pellegrini, M. (2011). Obsessive-compulsive disorder comorbidity: Clinical assessment and therapeutic implications. Frontiers in Psychiatry, 2(70), 1-11.

Panksepp, J., \& Watt, D. (2011). Why does depression hurt? Ancestral primary-process separation-distress (PANIC/GRIEF) and diminished brain reward (SEEKING) processes in the genesis of depressive affect. Psychiatry: Interpersonal \& Biological Processes, 74(1), 5-13.

Pedrabissi, L., \& Santinello, M. (1989). Verifica della validità dello STAI forma Y di Spielberger [Verification of the validity of the STAI, Form Y, by Spielberger]. Giunti Organizzazioni Speciali, 191$192,11-14$

Persons, J. B., \& Bertagnolli, A. (1999). Inter-rater reliability of cognitive-behavioral case formulations of depression: A replication. Cognitive Therapy and Research, 23, 271-283.

Persons, J. B., \& Tompkins, M. A. (1997). Cognitive-behavioral case formulation. In T. D. Eells (Ed.), Handbook of psychotherapy case formulation (pp. 314-339). Guilford Press.

Persons, J. B., Roberts, N. A., Zalecki, C. A., \& Brechwald, W. A. (2006). Naturalistic outcome of case formulation-driven cognitive-behavior therapy for anxious depressed outpatients. Behaviour Research and Therapy, 44(7), 1041-1051.

Rachman, S. (1977). The conditioning theory of fear acquisition: A critical examination. Behaviour Research and Therapy, 15, 375-387.

Rachman, S. (1993). Obsessions, responsibility and guilt. Behaviour Research and Therapy, 31, 149-154.

Rapee, R. M., Craske, M. G., Brown, T. A., \& Barlow, D. H. (1996). Measurement of perceived control over anxiety-related events. Behavior Therapy, 27(2), 279-293.

Rassin, E., Merckelbach, H., \& Muris, P. (2000). Paradoxical and less paradoxical effects of thought suppression: A critical review. Clinical Psychology Review, 20(8), 973-995.

Rimes, K. A., \& Watkins, E. (2005). The effects of self-focused rumination on global negative self-judgements in depression. Behaviour Research and Therapy, 43(12), 1673-1681. 
Rogers, Carl. (1977). On personal power: Inner strength and its revolutionary impact. Constable \& Company Limited.

Ruggiero, G. M., Caselli, G., \& Sassaroli, S. (2021). Case formulation as therapeutic process in CBT. Springer.

Ruggiero, G. M., Stapinski, L., Caselli, G., Fiore, F., Gallucci, M., Sassaroli, S., \& Rapee, R. (2012). Beliefs over control and meta-worry interact with the effect of intolerance of uncertainty on worry. Personality and Individual Differences, 53, 224-230.

Salkovskis, P. M. (1985). Obsessive-compulsive problems: A cognitive-behavioural analysis. Behaviour Research and Therapy, 23, 571-583.

Salkovskis, P. M. (1991). The importance of behaviour in the maintenance of anxiety and panic: A cognitive account. Behavioural Psychotherapy, 19, 6-19.

Salton, G., \& McGill, M. J. (1983). Introduction to modern information retrieval. McGraw-Hill.

Sammon, J. W. (1969). A nonlinear mapping for data structure analysis. IEEE Transactions on Computers, $18,401-409$.

Sanavio, E. (1988). Obsessions and compulsions: The padua inventory. Behaviour Research and Therapy, 26, 169-177.

Sassaroli, S., Caselli, G., \& Bassanini, R. G. M. (2017a). Procedure e protocollo di terapia LIBET seconda parte: fasi del protocollo e caso clinico Antonia A. Psicoterapia Cognitiva e Comportamentale, 32, 331-344.

Sassaroli, S., Caselli, G., Redaelli, C., \& Ruggiero, G. M. (2017b). Procedure e protocollo di terapia LIBET_prima parte: Le procedure ABC-LIBET, laddering e disputing. Psicoterapia Cognitiva $e$ Comportamentale, 23, 73-92.

Sassaroli, S., Caselli, G., \& Ruggiero, G. M. (2016). Un modello cognitivo clinico di accertamento e concettualizzazione del caso: Life themes and plans Implications of biased Beliefs-Elicitation and Treatment (LIBET). Psicoterapia Cognitiva e Comportamentale, 22, 183-197.

Sassaroli, S., Gallucci, M., \& Ruggiero, G. M. (2008). Low perception of control as a cognitive factor of eating disorders. Its independent effects on measures of eating disorders and its interactive effects with perfectionism and self-esteem. Journal of Behavior Therapy and Experimental Psychiatry, 39, 467-488.

Sassaroli, S., Lorenzini, R., \& Ruggiero, G. M. (2005). Kellian invalidation, attachment and the construct of “control.” In D. A. Winter \& L. L. Viney (Eds.), Personal construct psychotherapy. Advances in theory, practice and research (pp. 34-42). Whurr Publishers.

Schneider, B. H., \& Byrne, B. M. (1987). Individualizing social skills training for behavior-disordered children. Journal of Consulting and Clinical Psychology, 55, 444-445.

Schore, A. N. (2012a). The science of the art of psychotherapy. W. W. Norton \& Company Inc.

Schore, A. N. (2012). Bowlby's environment of evolutionary adaptedness. Recent studies on the interpersonal neurobiology of attachment and emotional development. In D. Narvaez, J. Panksepp, A. N. Schore, \& T. R. Gleason (Eds.), Evolution, early experience and human development from research to practice (pp. 31-73). Oxford University Press.

Schulte, D., Künzel, R., Pepping, G., \& Schulte-Bahrenberg, T. (1992). Tailor-made versus standardized therapy of phobic patients. Advances in Behaviour Research and Therapy, 14(2), 67-92.

Shafran, R., Cooper, Z., \& Fairburn, C. G. (2002). Clinical perfectionism: A cognitive-behavioural analysis. Behaviour Research and Therapy, 40, 773-791.

Shapiro, D. H., \& Astin, J. A. (1998). Control therapy: An integrated approach to psychotherapy, health, and healing. John Wiley.

Shapiro, F. (2017). Eye movement desensitization and reprocessing (EMDR) therapy: Basic principles, protocols, and procedures. Guilford Press.

Siegel, D. (1999). The developing mind: Toward a neurobiology of interpersonal experience. Guilford Press.

Sloman, S. A. (2002). Two systems of reasoning. In T. Gilovich, D. Griffin, \& D. Kahneman (Eds.), Heuristics and biases (pp. 379-396). Cambridge University Press.

Spada, M. M., Caselli, G., \& Wells, A. (2013). A triphasic metacognitive formulation of problem drinking. Clinical Psychology \& Psychotherapy, 20(6), 494-500.

Spielberger, C. D., Gorsuch, R. L., Lushene, R., Vagg, P. R., \& Jacobs, G. A. (1983). Manual for the state-trait anxiety inventory (Form Y). Consulting Psychologists Press.

Stanovich, K. E. (1999). Who is rational? studies of individual differences in reasoning. Erlbaum. 
Stanovich, K. E., \& West, R. F. (2002). Individual differences in reasoning: Implications for the rationality debate. In T. Gilovich, D. Griffin, \& D. Kahneman (Eds.), Heuristics and biases (pp. 421-440). Cambridge University Press.

Sternberger, L. G., \& Burns, G. L. (1996). Obsessions and compulsions: Psychometric properties of the Padua inventory with an American college population. Behaviour Research and Therapy, 28, $341-345$.

Strauman, T. J., Vieth, A. Z., Merrill, K. A., Kolden, G. G., Woods, T. E., Klein, M. H., Papadakis, A., Schneider, K. L., \& Kwapil, L. (2006). Self-system therapy as an intervention for self-regulatory dysfunction in depression: A randomized comparison with cognitive therapy. Journal of Consulting and Clinical Psychology, 74, 367-376.

Sturmey, P. (Ed.). (2009). Clinical case formulation: Varieties of approaches. John Wiley \& Sons.

Thwaites, R., \& Freeston, M. H. (2005). Safety-seeking behaviours: Fact or function? How can we clinically differentiate between safety behaviours and adaptive coping strategies across anxiety disorders? Behavioural and Cognitive Psychotherapy, 33(2), 177-188.

Tiffany, S. (1990). A cognitive model of drug urges and drug abuse behavior: Role of automatic and nonautomatic processes. Psychological Review, 84, 127-190.

van der Kolk, B. A. (1996). The complexity of adaptation to trauma: Self-regulation, stimulus discrimination, and characterological development. In B. A. van der Kolk, A. C. McFarlane, \& L. Weisaeth (Eds.), Traumatic stress: The effects of overwhelming experience on mind, body, and society (pp. 182-213). Guilford Press.

Veronese, G., Pepe, A., \& Afana, A. (2016). Conceptualizing the well-being of helpers living and working in war-like conditions: A mixed-method approach. International Social Work, 59, 938-952.

Veronese, G., Pepe, A., \& Vigliaroni, M. (2019a). An exploratory multi-site mixed-method study with migrants at Niger transit centers: The push factors underpinning outward and return migration. International Social Work. https://doi.org/10.1177/0020872818819736

Veronese, G., Pepe, A., Addimando, L., Sala, G., \& Vigliaroni, M. (2019b). "It's paradise there, I saw it on TV": Psychological wellbeing, migratory motivators, and expectations of return among West African migrants. Nordic Psychology, 72, 33-50.

Vieth, A. Z., \& Trull, T. J. (1999). Family patterns of perfectionism: An examination of college. Journal of Personality Assessment, 72(1), 49-67.

Wells, A. (2008). Metacognitive therapy for anxiety and depression. Guilford Press.

Wells, A., \& Mathews, G. (1994). Attention and emotion: A clinical perspective. Erlbaum.

Whaley, S. E., Pinto, A., \& Sigman, M. (1999). Characterizing interactions between anxious mothers and their children. Journal of Consulting and Clinical Psychology, 67, 826.

Winter, D. A., \& Viney, L. L. (Eds.). (2005). Personal construct psychotherapy. Advances in theory, practice and research. Whurr Publishers.

Woodruff-Borden, J., Morrow, C., Bourland, S., \& Cambron, S. (2002). The behavior of anxious parents: Examining mechanisms of transmission of anxiety from parent to child. Journal of Clinical Child and Adolescent Psychology, 31, 364-374.

Young, J. E., Klosko, J. S., \& Weishaar, M. (2003). Schema therapy: A practitioner's guide. Guilford.

Publisher's Note Springer Nature remains neutral with regard to jurisdictional claims in published maps and institutional affiliations.

\section{Authors and Affiliations}

\section{Sandra Sassaroli ${ }^{2,3,4} \cdot$ Gabriele Caselli ${ }^{2,3,4,7} \cdot$ Giovanni Mansueto ${ }^{3,4}$. Sara Palmieri ${ }^{3,4}$. Alessandro Pepe ${ }^{5}$. Guido Veronese ${ }^{5,6}$. Giovanni M. Ruggiero ${ }^{1,2,3,4}$ (i)}

1 "Psicoterapia Cognitiva e Ricerca" Cognitive Psychotherapy School and Research Center, Milano, Foro Buonaparte 57, 20121 Milan, Italy

2 "Studi Cognitivi" Cognitive Psychotherapy School and Research Center, Foro Buonaparte 57, 20121 Milan, Italy 
3 Sigmund Freud University, Ripa di Porta Ticinese 77, 20143 Milan, Italy

4 Sigmund Freud University, Freudplatz 1, Messestraße 1, 1020 Wien, Austria

5 Department of Human Science and Education, University of Milano-Bicocca, Milan, Italy

6 Department of Psychology, Stellenbosch University, Matieland, Stellenbosch 7602, South Africa

7 Department of Psychology, London South Bank University, 03 Borough Rd, London SE1 0AA, UK 